Jubb, J., Bensing, J.M. The sweetest pill to swallow: how patient neurobiology can be harnessed to maximise placebo effects. Neuroscience and Biobehavioral Reviews: 2013, 37(10

\begin{tabular}{|l|l|}
$\begin{array}{l}\text { Postprint } \\
\text { Version }\end{array}$ & 1.0 \\
\hline Journal website & $\underline{\text { http://www.sciencedirect.com/science/article/pii/S0149763413002157 }}$ \\
\hline Pubmed link & $\underline{\text { http://www.ncbi.nlm.nih.gov/pubmed/24055773 }}$ \\
\hline DOI & $10.1016 /$ j.neubiorev.2013.09.006 \\
\hline
\end{tabular}

This is a NIVEL certified Post Print, more info at http://www.nivel.eu

\title{
The sweetest pill to swallow: How patient neurobiology can be harnessed to maximise placebo effects
}

\author{
JAYNE JUBB , JOZIEN M. BENSING \\ NIVEL (The Netherlands Institute for Health Services Research), Otterstraat 118-124, 3513 \\ CR Utrecht, The Netherlands
}

\begin{abstract}
The burgeoning interest in placebo effects over the last 10-15 years has fallen into two main research areas: elucidation of the neurobiological mechanisms recruited following placebo administration, and investigations into the situations and contexts in which placebo effects are evoked. There has been little attention focused on bridging these two i.e. how to actively translate and apply these neurobiological mechanisms into daily clinical practice in a responsible way. This article addresses this gap, first through a narrative review of the last 15 years of neuroscience findings with special attention focussed on the elucidation of the neurotransmitters, pathways and mechanisms involved in placebo effects, and secondly, at how these psycho(neuro)biological effects could be harnessed in medical care.
\end{abstract}

\section{INTRODUCTION}

Placebos are a conundrum.

How can something which by definition is an inert treatment devoid of any pharmaceutical properties (e.g. a sugar pill, saline injection, or even words, rituals and meanings) produce a change in a patient?

The mention of the word 'placebo' is often immediately associated with placation and deception (Bensing and Verheul, 2010, de Craen et al., 1999 and Verheul et al., 2010). In spite of the bad press they receive, surveys carried out in the United States (Berger, 1999 and Sherman and Hickner, 2007), Denmark (Hrobjartsson and Norup, 2003) and Israel (Nitzan and Lichtenberg, 2004) reveal that placebos are being fairly widely administered in medical practice. In spite of the placebos' dubious history, the neuroscientific investigations from the last 15 years (see Box 1 for search strategy and selection criteria) have shown that the placebo effect is in fact a real biological phenomenon due to the psychosocial context of the patient and the therapy (Finniss 
Jubb, J., Bensing, J.M. The sweetest pill to swallow: how patient neurobiology can be harnessed to maximise placebo effects. Neuroscience and Biobehavioral Reviews: 2013, $37(10$
Part 2), 2709-2720

et al., 2010 and Price et al., 2008). By their very definition placebo effects therefore bridge physiological processes with the interaction-rich environment in which they occur, and yet the practical potential in this overlap has not yet been tapped.

\section{[Box 1]}

In this article we would like to put forward how the knowledge gleaned from placebo effect research can provide valuable added benefits to daily medical situations when used in an open, ethical and responsible way.

After the initial title and abstract screening, the publications fell into categories: primary research papers, and reviews. Primary research papers were defined as those containing experimental evidence pertaining to placebo effect research. Reviews (including books) included summaries of findings from primary research papers. Other papers were also garnered via forward searching (citation index to see how often and by whom this paper had been cited) and backward searching (what publications did this author include that we may have missed) using the publications extracted from the database searches. Publications were included if they contained experimentally supported findings for neural substrates and neural mechanisms. Publications were excluded if they: included only historical and theoretical information (i.e. no experimental support); were for placebo-controlled trials for pharmaceutical testing; did not have a neuroscience-related content. This yielded around 200 publications and it is on the basis of these that this paper is written. The literature search itself was thus limited to the neuroscientific studies underlying placebo effects. These were then further supplemented with scientific studies from a wide variety of disciplines to illustrate examples and possibilities of clinical applications of placebo effects.

\subsection{Hidden in plain sight: open-hidden paradigm}

It is sobering to realise that until post-World War II, modern medicine was essentially the medicine of placebo effects (Kaptchuk, 1998, Raicek et al., 2012 and Shapiro and Shapiro, 1997). Placebo effects became more scientifically visible when Beecher (1955) reported that $35 \%$ of patients responded positively to placebo treatment. His choice to categorise placebo effects as something to be baselined - as opposed to investigating the occurrence of the effects themselves resulted in the adoption of the randomised controlled trial (RCT), and later, the double-blind placebo-controlled clinical trial.

In recent years, meta-analyses of published data disrupted emerging theories when they implied that placebo effects were actually very small, and even non-existent (Hrobjartsson and Gøtzsche, 2001, Hrobjartsson and Gøtzsche, 2004a, Hrobjartsson and Gøtzsche, 2004b, Hrobjartsson and Gøtzsche, 2006, Hrobjartsson and Gøtzsche, 2007a and Hrobjartsson and Gøtzsche, 2007b). As a result of this, differences came to light between placebo effects observed during experimental conditions and those in clinical trials (Hrobjartsson and Gøtzsche, 2010, Vase et al., 2002 and Vase et al., 2009). In clinical trials, it is the new drug that is under scrutiny, and the placebo becomes a method of statistical differentiation; in experimental conditions designed for studying placebo effects, it is the placebo effect itself that is being investigated. It has now been established that placebo effects are larger under experimental conditions than clinical trials, and are especially present in placebo analgesia research (Hrobjartsson and Gøtzsche, 2010). The placebo effect is thus a real 
Jubb, J., Bensing, J.M. The sweetest pill to swallow: how patient neurobiology can be harnessed to maximise placebo effects. Neuroscience and Biobehavioral Reviews: 2013, 37(10 Part 2), 2709-2720

psychobiological occurrence which does not denote natural history progression (spontaneous remissions), patient bias and regressions to mean. The latter are commonly found in the clinically executed placebo-controlled pharmaceutical trials. The quantitative magnitude of the placebo effect was revealed by Levine and coworkers during post-operative dental pain studies (Levine et al., 1981 and Levine and Gordon, 1984). Telling patients that a painkiller was being administered, whereas in fact a saline (placebo) solution was being given, was found to be as potent as a hidden intravenous 6-8 mg dose of morphine. For the patient, the sight and presence of a doctor openly injecting a painkiller was a potent analgesic in itself.

These studies by Levine et al. introduced for the first time the open-hidden experimental design which has since been used widely in clinical (placebo) settings (Amanzio et al., 2001, Benedetti et al., 2003b and Colloca et al., 2004). In the most straightforward open set-up, an injection (e.g. a verum analgesic) is given in full view of the patient; in the hidden set-up, the treatment is administered via a computer-operated infusion pump, where the doctor is absent and the patient is unaware when the pharmacotherapy is being administered. If a drug is effective and the pharmacological action is the cause of the improvement, there should be no difference between the open and the hidden injections. The beauty of this openhidden paradigm is that by eliminating extraneous surrounding components it provides a clean measure of the true pharmacological drug action under investigation. The difference between the two forms of administration (Fig. 1) comprises a black box of psychosocial-neurobiological constituents ('placebo effect components') inherent in eliciting placebo responses. There has recently been a call for creative experimental efforts to rigorously assess the clinical significance of placebo interventions and investigate these component elements that may contribute to the therapeutic benefit of placebo effects (Hróbjartsson et al., 2011).

\section{[FIGURE 1]}

\subsection{Interaction-enhanced pharmacology}

In a clinical setting, a drug is most commonly administered in full-view of the patient, with their knowledge that it is being given. The open-hidden experimental set-up showed how the very act of administration triggers the placebo response component, in analgesia, Parkinson's disease, anxiety and depression (Colloca et al., 2004). This means that it could feasibly be an ever-present part of the total therapeutic effect in which overall outcome is greater than that produced purely by the chemical component(s). In daily clinical practice this means that the therapeutic effect produced by many treatments is inseparable from the context in which it is given and the doctor (practitioner or medical personnel) giving it. The fact that placebo effects exist in addition to the pharmacological action of the drug (Fig. 1) would seem to make them amenable to being used more often than they currently are. We have termed this 'interaction-enhanced pharmacology'. There is no unethical misleading or deception of patients since no fake drugs or other placebo substance need to be administered. Instead there is a harnessing of constituents, both in the doctor as well as in the patient through their mutual interaction to elicit the patient's innate capabilities, and thus enhance the effects of existing medical therapies. 
Jubb, J., Bensing, J.M. The sweetest pill to swallow: how patient neurobiology can be harnessed to maximise placebo effects. Neuroscience and Biobehavioral Reviews: 2013, 37(10 Part 2), 2709-2720

\section{THE PATIENT AS CENTRAL FACTOR}

When a patient steps into the doctor's office, neurobiological processes are triggered in reaction to psychosocial components before any pharmacotherapy has even been administered. Although a complex intertwining of these factors is actually present, various components have been established from placebo effect research that are involved in this interaction-enhanced pharmacology. These include:

Treatment context

- Patient-doctor (patient-practitioner) interaction.

- Choice of intervention method used.

Psychological processes

- Expectancy.

- Conditioning and reinforced expectancies.

Neurophysiological mechanisms

- Opioidergic pathways.

- Dopaminergic pathways.

- Cannabinoidergic pathways.

\subsection{Treatment context}

\subsubsection{Patient-practitioner interaction}

In the whole psychosocial context surrounding medical treatment, the most powerful contributing factor is probably the patient-doctor interaction (Barrett et al., 2007, Brody, 2009 and Di Blasi et al., 2001). This interaction lies at the heart of medicine (de Haes and Bensing, 2009), is present in almost every step of medical care, and is known to play an important role in the outcome of illness (Bass et al., 1986, Greenfield et al., 1985, Starfield et al., 1981, Stewart et al., 1979 and Stewart, 1995). Patient-practitioner communication has to address the patient's 'double need' (Bensing et al., 1996 and Engel, 1988): to know and understand, and to feel known and understood. Doctor-patient communication has been shown to play an important role in fulfilling both these needs (Bensing and Dronkers, 1992). Affective communication is targeted at establishing a good therapeutic relationship between the practitioner and the patient (Bensing et al., 1996), and there have been many qualitative and observational studies around the characteristics necessary for a 'good doctor' e.g. warmth, eye contact, active listening, empathy, thoughtful silences, and leaving room for the patient to tell their story (Epstein and Street, 2007, Roter and Hall, 2006, Roter et al., 2006 and Stewart, 1995). An overview of the literature shows that 'although there is much inconsistency regarding emotional and cognitive care, one relatively consistent finding is that physicians who adopt a warm, friendly, and reassuring manner are more effective than those who keep consultations formal 
Jubb, J., Bensing, J.M. The sweetest pill to swallow: how patient neurobiology can be harnessed to maximise placebo effects. Neuroscience and Biobehavioral Reviews: 2013, 37(10 Part 2), 2709-2720

and do not offer reassurance.' (Di Blasi et al., 2001). By employing such communication techniques the patient feels cared for (Bensing et al., 1996, Epstein and Street, 2007 and Neumann et al., 2010).

The notion of the doctor as the drug (Balint, 1957) and the doctor as a walking placebo (Brody, 1997) have been known for some time, yet this 'factor X' (White, 1988) has been extensively demonstrated by Kaptchuk and co-workers. Embedded within the placebo arm of an intervention study on the effects of acupuncture on irritable bowel syndrome (IBS) symptoms was a trial that examined the effects of three different versions of patient-doctor interaction on the effectiveness of placebo acupuncture (Kelley et al., 2009). The group with an augmented patient-practitioner relationship reported symptom improvement on a magnitude as great as any medication approved for IBS by the American Food and Drug Administration (FDA) (Kaptchuk et al., 2009). Very recently, this same group has used fMRI to investigate the neural activity in the doctor whilst the patient was experiencing pain (Jensen et al., 2013). The doctor's ability to take the patient's perspective showed increased brain activations in areas associated with empathy, expectations and reward processing. We shall see later in this section (and also in Section 2.3) that expectations and reward processing are paramount for eliciting placebo responses in the patient.

It would thus seem that it is the quality of the patient-practitioner interaction that accounts for a sizeable chunk of the effect seen in placebo responses (Di Blasi et al., 2001), and as such this is a component in interaction-enhanced pharmacology worthy of making more use of.

\subsubsection{Choice of intervention}

The method with which an intervention is delivered is also influential. Different placebos have been found to modulate different effects. For example, placebo pills are better for sleep, and sham needles are better for pain ( Barrett et al., 2007 and Kaptchuk et al., 2000). When pills are used as a placebo intervention, the shape (Buckalew and Ross, 1981), colour (de Craen et al., 1996), recognised brandname (Branthwaite and Cooper, 1981), and financial cost ( Geuter et al., 2013 and Waber et al., 2008) of pills can in themselves lead to clinical improvements as well as to the patient becoming pharmacologically conditioned. The differences between a placebo pill and a placebo sham device have also been investigated (Kaptchuk et al., 2006) with sham acupuncture patients exhibiting a significant reduction in pain compared to the placebo pill group. Even the act of taking part in a clinical trial can result in improvement (the Hawthorne effect) because of the examinations the person undergoes, the attention they receive from medical personnel and the expectancies triggered by taking part in a new therapy program (Last, 1983).

Surgery is perhaps the most powerful delivery method of all in terms of provoking a strong placebo effect (Benedetti et al., 2004a, de la Fuente-Fernández et al., 2001, de la Fuente-Fernandez et al., 2004 and Wager et al., 2004). Historically there have been well-cited examples of sham surgery to perform artery ligation (Cobb et al., 1959 and Dimond et al., 1958) for angina pectoris, laser myocardial revascularisation for people with coronary heart disease (Rana et al., 2005), sham arthroscopic surgery 
Jubb, J., Bensing, J.M. The sweetest pill to swallow: how patient neurobiology can be harnessed to maximise placebo effects. Neuroscience and Biobehavioral Reviews: 2013, 37(10 Part 2), 2709-2720

for osteoarthritis of the knee (Moseley et al., 2002) and intra-articular injections of saline solution for knee pain (Rosseland et al., 2004).

The most striking experiment in the Parkinson's neuro-placebo genre concerned the transplantation of human fetal mesencephalic (Freed et al., 2001, Husten, 1999 and McRae et al., 2004) and nigrostriatal (Olanow et al., 2003) cells. Patients who thought they had undergone the active treatment (irrespective of whether they had received an actual transplant or had the sham surgery) showed significant improvements in perceived physical function and perceived social support. In those patients who continued to believe that they had received active treatment, this benefit was sustained for the 12 month duration of the study. Blinded medical evaluators detected significant improvements in all domains of motor function and activities of daily living in the patients who thought they had received active treatment.

\subsection{Psychological processes}

From a psychological point of view, two principal mechanisms are well supported that contribute to the production of placebo effects. The first mechanism involves expectancy and the second involves classical conditioning.

\subsubsection{Expectancies}

In general terms, expectation is a cognitively driven process that prepares the body and mind to anticipate an event in order to be better able to cope with it. In healthcare terms, expectation can encompass an inherent sense of hope, anticipation, and the desire for relief around what will happen as a result of treatment (Crow et al., 1999, Kirsch, 1985, Kirsch, 2004 and Stewart-Williams and Podd, 2004), but it can also involve negative anticipation in the form of anxiety, fear or repulsion. In this case, this is termed 'nocebo effect' and is discussed later (Section 2.4).

Enhancing patients' expectations has been shown to significantly influence health outcomes (Crow et al., 1999 and Di Blasi et al., 2001). Something as simple as the words used to instruct the patient can have very clear repercussions on the patient's expectations (Kirsch, 1985). For example, the use of positive expectation ('This is a powerful painkiller') leads to analgesia (Amanzio and Benedetti, 1999, Benedetti et al., 1999, Price et al., 1999 and Vase et al., 2003). The clarity of instructions is also important because subtle changes in information given via the words used can influence the magnitude of the placebo effect. 'You may receive an active or a placebo agent' (Verne et al., 2003) produces smaller placebo responses than 'The agent you have been given is known to significantly reduce pain in some patients' (Vase et al., 2003).

\subsubsection{Conditioning and reinforced expectancies}

The use of Pavlovian conditioning is a powerful means for inducing physiological changes. Verbal, conditioned and observational cues can create strong expectancies that influence the placebo response. Reported examples of pairing a conditioning stimulus with an associated health outcome are: 
Jubb, J., Bensing, J.M. The sweetest pill to swallow: how patient neurobiology can be harnessed to maximise placebo effects. Neuroscience and Biobehavioral Reviews: 2013, 37(10 Part 2), 2709-2720

- A flavoured drink being associated with the immunosuppression of cyclosporine A (Goebel et al., 2002 and Goebel et al., 2005).

- Relief from allergic rhinitis (also via a flavoured drink; Goebel et al., 2009).

- Conditioned hypoglycaemia (via injection of insulin in shock therapy; Lichko, 1959 and Stockhorst et al., 1999).

- Conditioned growth hormone increase (associated stimulus here was the injection used to administer the hormone; Benedetti et al., 2003a).

This means that patients' previous experiences can not only shape their conscious expectations, but can also lead to conditioned responses. An interesting practical application of how a conditioned response can be re-conditioned has been investigated in cancer chemotherapy. Here anticipatory nausea and vomiting are unpleasant side effects frequently experienced as a result of chemotherapy, with the prevalence ranging from 10-63\% (Stockhorst et al., 2000). Even with anti-emetic treatments it can reach 59\% (Tyc et al., 1997). This is believed to be a conditioned nocebo effect (see also Section 2.4) (Andrykowski and Otis, 1990,Bernstein, 1991, Jacobsen et al., 1993, Nesse et al., 1980 and Stockhorst et al., 1998). The conditioning arises from a pairing of contextual stimuli (e.g. an odour present in the clinical environment; Nesse et al., 1980) with the resultant nausea and vomiting from the chemotherapy. However, there is evidence to suggest that this nocebo response is a learning phenomenon mediated by conditioning mechanisms, and as such that this conditioning can be relearned and reconditioned through a technique called overshadowing (Stockhorst et al., 1998). Following such a reconditioning training, patients showed no anticipatory nausea to the chemotherapy in contrast to $25 \%$ of the control subjects who did not undergo the overshadowing conditioning, and suffered from anticipatory nausea (Klosterhalfen et al., 2005, Stockhorst et al., 1998,Stockhorst et al., 2006 and Stockhorst et al., 2007). This kind of conditioning, based on psychosocial context components can thus be a very useful tool from a therapeutic perspective.

When a placebo is given as a drug substitute for the first time, the placebo response elicited may be present and it may be small. However, it is known that placebos are more effective when given as the drug-substitute once the original drug has been effectively experienced than when administered for the first time in the absence of a drug (Batterman, 1966, Batterman and Lower, 1968, Laska and Sunshine, 1973 and Sunshine et al., 1964). If a placebo is given after two previously effective experiences with an analgesic, the placebo analgesic response is much greater (Amanzio and Benedetti, 1999), the magnitude of the placebo response being dependent on the previous analgesic experience(s) (Colloca and Benedetti, 2006). This preconditioning has also been responsible for inducing robust placebo responses in Parkinson's patients (Benedetti et al., 2004a, Benedetti et al., 2009, de la FuenteFernández et al., 2001 and Strafella et al., 2006).

These conditioning and reinforced expectancies have also been applied within the sports' medicine environment (Benedetti et al., 2007b). An increase in quadriceps muscle performance and decreased muscle fatigue was achieved by a pre- 
Jubb, J., Bensing, J.M. The sweetest pill to swallow: how patient neurobiology can be harnessed to maximise placebo effects. Neuroscience and Biobehavioral Reviews: 2013, 37(10 Part 2), 2709-2720

conditioning coupling of a 'high caffeine dose' (really a placebo) with reducing the weight actually lifted (Pollo et al., 2008). In this way the coupling of the 'caffeine' with the experience of being able to lift a heavier weight, can push muscular performance further.

Pharmacological conditioning is an effect that can occur whenever patients take pills which elicit desirable (and sometimes undesirable) effects. The shape, size, colour and taste of a pill can become associated with improvement very easily. A drug is not the only paired-stimulus that can occur. There are many other stimuli associated with hospitals (sights, sounds, smells), the equipment used, the diagnostic techniques employed, and the medical personnel themselves.

\subsection{Neurophysiological mechanisms}

Three main neurotransmitters have been linked, so far, to the psychoneurophysiological mechanisms involved in the generation of placebo effects: opioids, dopamine and cannabinoids. Opioid-mediated pathways are employed in expectancy and conditioning; dopamine-mediated mechanisms in reward, motivation and expectancy of the reward. The most fruitful neurobiological models for studying placebo response have emerged from pain and Parkinson's disease. In pain

modulation, the neural networks involved are the opioid-cholecystokinin-dopamine systems (Fig. 2a), with the role of cannabinoid (CB1) receptors in nonopioidmediated placebo analgesia recently established (Benedetti et al., 2011); in Parkinson's disease it is part of the basal ganglia circuitry that produces the placebo response (Fig. 2b). In addition to opioids, dopamine and cannabinoids, investigations into the possible involvement of serotonergic pathways (Benedetti et al., 2005, Leuchter et al., 2002 and Mayberg et al., 2002) have been stimulated by placebo responses in antidepressant trials (Andrews, 2001, Khan et al., 2000 and Walsh et al., 2002) plus two meta-analyses (Brunoni et al., 2009 and Rief et al., 2009). Oxytocin (OXY) and nitric oxide (NO) have both been postulated as possible mediators of the placebo response, (OXY: Breton et al., 2008, Enck and Klosterhalfen, 2009 and Yang et al., 2007; NO: Fricchione and Stefano, 2005 and Stefano et al., 2001) but as yet little has been elucidated. The state-of-theart knowledge is thus far that opioid-, dopamine-, and cannabinoid-mediated pathways are recruited in the production of placebo effects. Opioid- and cannabinoid-mediated pathways are employed in expectancy and conditioning (Benedetti et al., 2011, Colloca and Benedetti, 2005, de la Fuente-Fernández et al., 2001, Finniss and Benedetti, 2005, Geuter et al., 2013,Levine et al., 1978, Mayberg et al., 2002, Petrovic et al., 2002, Price et al., 2008, Volkow et al., 2003 and Zubieta et al., 2005) while dopamine-mediated mechanisms are employed in reward, motivation and expectancy of the reward (Benedetti et al., 2004a, Benedetti et al., 2009, de la Fuente-Fernandez and Stoessl, 2002 and Scott et al., 2008).

\section{[FIGURE 2]}

\subsubsection{Expectancy: opioidergic pathways}

The initial link between opioid involvement and expectancy was established with pharmacological studies. These showed that expectancy triggered the activation of opioid-mediated analgesic pathways (Gracely et al., 1983 and Grevert et al., 1983) 
Jubb, J., Bensing, J.M. The sweetest pill to swallow: how patient neurobiology can be harnessed to maximise placebo effects. Neuroscience and Biobehavioral Reviews: 2013, 37(10 Part 2), 2709-2720

and that these could be blocked by the opioid antagonist, naloxone (Gracely et al., 1983, Grevert et al., 1983, Levine and Gordon, 1984 and Levine et al., 1978). The advent of neuroimaging (functional magnetic resonance imaging, fMRI, and positron emission tomography, PET) led to the establishment of the cerebral areas involved in placebo analgesia (Bingel et al., 2006, Bingel et al., 2011,Kong et al., 2006, Petrovic et al., 2002, Petrovic et al., 2005, Raz et al., 2005, Scott et al., 2008, Wager et al., 2004, Zubieta et al., 2005 and Zubieta et al., 2006), summarised in Table 1 and Figs. 2a and $2 \mathrm{~b}$. fMRI and PET research yielded the important discoveries that placeboinduced expectation of analgesia triggers the release of the patient's own endogenous opioids (Bingel et al., 2006, Kong et al., 2006, Petrovic et al., 2002,Petrovic et al., 2005, Raz et al., 2005, Scott et al., 2008, Wager et al., 2004, Zubieta et al., 2005 and Zubieta et al., 2006), and that this recruits the same opioid-mediated pathway triggered by pharmaceutical analgesics (Petrovic et al., 2002).

\section{[TABLE 1]}

\subsubsection{Motivation and reward: dopaminergic pathways}

When motivation or reward is involved, a dopaminergic pathway is recruited. Dopamine's (DA) involvement in reward and expectation of reward has been known since Garris et al. (1999) published their intracranial self-stimulation study. This provided evidence that expectation of rewards alone will elicit DA release in the nucleus accumbens (NAC), and dopamine has now an established role in reward and expectation mechanisms in general ( Kelley and Berridge, 2002 and Tobler et al., 2005).

Since reduced pain, for example, can be perceived as a reward, placebos promising an expected reward of pain relief have been demonstrated to first release dopamine in the NAC which then subsequently trigger the activation of the downstream adaptive (e.g., opioid) responses to elicit an analgesic response (Scott et al., 2008). This NAC dopamine release positively correlates with the magnitude of endogenous opioid release in the NAC, ventral putamen, amygdala, aINS, posterior insula (pINS), and rACC. The magnitude of DA activation in the NAC correlates positively with the individual's expectations of analgesia and the magnitude of analgesia experiences.

Much valuable information concerning DA involvement in placebo processes has come from the study of patients with Parkinson's disease (PD), in which placebo effects are known to be common (Goetz et al., 2000 and Shetty et al., 1999). Since the first PD symptoms arise only when approximately $80 \%$ of the dopamine (DA) activity has been lost (Morrish et al., 1996) it was not known if the effects observed could be mediated by a nigrostriatal system in which there is pathological degeneration. Elegant research carried out using PET (de la Fuente-Fernández et al., 2001 and de la Fuente-Fernández et al., 2002), repetitive transcranial magnetic stimulation (rTMS) (Strafella et al., 2006), and single neuron studies (Benedetti et al., 2004a and Benedetti et al., 2009) has established that this same (damaged) basal ganglia circuitry STN-SNr-VA/VLa is necessary for the generation of placebo effects (STN, subthalamic nucleus; SNr, substantia nigra pars reticulata; VA, ventral anterior thalamus; VLa, ventral lateral thalamus).

The reward of increased movement, using the Parkinson's disease model, also elicits a dopaminergic pathway. PET measurements demonstrated a $>200 \%$ increase in 
Jubb, J., Bensing, J.M. The sweetest pill to swallow: how patient neurobiology can be harnessed to maximise placebo effects. Neuroscience and Biobehavioral Reviews: 2013, 37(10 Part 2), 2709-2720

extracellular dopamine concentration released into the striatum when a PD patient believed a placebo to be the DA agonist apomorphine (a powerful anti-Parkinsonian agent) (de la Fuente-Fernández et al., 2001). This was comparable to the response to the DA agonist amphetamine which results in release of endogenous DA in healthy subjects. In this study, all PD patients exhibited an increased DA release in the ventral striatum (NAC), but only those who showed improved motor activity showed larger amounts of DA in the dorsal (motor) striatum (nucleus caudatus and putamen) (Fig. 2a). These findings were confirmed in another PET study of PD patients undergoing sham (fake) repetitive transcranial magnetic stimulation (rTMS) (Strafella et al., 2006). Placebo-induced changes in NAC activity did not differ significantly between PD patients who experienced increased movement and those who did not (de la Fuente-Fernández et al., 2001).

Studies at the level of single neurons (using an implanted deep brain stimulation, DBS, electrode) have shown a decrease in neuronal firing in the substantia nigra pars reticulata (SNr) and increases in ventral anterior thalamus (VA) and ventral lateral thalamus (VLa) activity (Fig. 1a) (Benedetti et al., 2009). Placebo non-responders showed either no changes in this circuit or only partial changes in the STN confirming that the whole STN-SNr-VA/VLa is necessary for a clinical (behavioural) benefit to be seen. For example, recording of single neuron activity showed changes in neural firing correlated closely with clinical (e.g. wrist rigidity) and subjective improvement ("I feel better") (Benedetti et al., 2004a), but no firing change occurred when there was no clinical placebo response. It appears the expectation of the reward of movement is sufficient to trigger DA release in the NAC (ventral striatum) in PD patients, but that the tangible motor differences lie in the magnitude of activation of the dorsal striatum (Benedetti et al., 2009 and de la Fuente-Fernández et al., 2002).

This study (Benedetti et al., 2009) indicates the combination of several placebogenic components in interaction-enhanced pharmacology. Following surgery (powerful placebo effect) to implant the DBS electrode, a placebo believed to be apomorphine (positive expectation; reward of increased movement since apomorphine is an effective anti-Parkinson drug) was administered. The outcomes are that patients reported an increased feeling of well-being, and muscle rigidity at the wrist was reduced. This latter was independently assessed by a neurologist blinded to the experiment using the Unified Parkinson's Disease Rating Scale (UPDRS). The effects lasted for 30-45 min due to ethical constraints limiting the intraoperative measurements (Benedetti et al., 2009).

\subsubsection{Cannabinoidergic pathways}

It has been known since Gracely et al. (1983) and Grevert et al. (1983) early work with opioid receptor antagonist challenges, that a time-dependant, non-opioid component could be present in placebo analgesia. The fact that it was not naloxone (an opioid antagonist) reversible, suggested mediation via a nonopioidergic pathway. This nonopioid pathway was further reinforced in experiments with nonsteroidal anti-inflammatory drugs (NSAIDs) (Amanzio and Benedetti, 1999): when conditioning took place with NSAID ketorolac, naloxone did not abolish the analgesic effect. With increasing evidence that NSAIDs interact with endocannabinoids (Fowler, 2007 and Shimizu, 2009) and cyclooxygenase-2 (Rouzer 
Jubb, J., Bensing, J.M. The sweetest pill to swallow: how patient neurobiology can be harnessed to maximise placebo effects. Neuroscience and Biobehavioral Reviews: 2013, 37(10 Part 2), 2709-2720

and Marnett, 2008), the endocannabinoids became a pathway of interest for their possible role in the placebo analgesic effects of NSAIDs. Recently, Benedetti and coworkers have established the role of cannabinoid (CB1) receptors in this nonopioid placebo analgesia (Benedetti et al., 2011). Using rimonabant as the CB1 receptor antagonist, nonopioid analgesic responses were blocked, but rimonabant was ineffective on opioid placebo responses. These findings show the involvement of the CB1 receptors, but the actual site of action in the brain has not yet been elucidated.

\subsection{Reduction of counteracting effects for interaction-enhanced pharmacology}

Any intervention that is non-verum and yet has positive effects, is called placebo, but any intervention that is non-verum and yet has negative effects, is called nocebo. Just as positive expectancies play a role for maximising the use of placebo effect mechanisms, negative expectancies in the form of fears and anxieties can produce socalled 'nocebo' effects. For example, in analgesia studies the administration of a nocebo results in an increase in pain (hyperalgesia).

It has been found that when a patient openly sees the analgesic infusion of morphine or diazepam being interrupted, relapse of pain occurs faster and pain intensity is greater than when the infusion is discontinued covertly (Benedetti et al., 2003a, Benedetti et al., 2007a and Colloca et al., 2004). In anxiety studies on patients with high anxiety levels following surgery, the anxiolytic diazepam was administered both openly and hidden (Amanzio et al., 2001 and Benedetti et al., 2003b). In the open group there was a definite decrease in anxiety; in the hidden group diazepam was totally ineffective. Interruption of treatment was also tested: in the open condition anxiety increased significantly, whereas in the hidden condition it did not change. This open-hidden design methodology has also been carried out with Parkinson's disease (Benedetti et al., 2004b and Lanotte et al., 2005) and addiction studies (Volkow et al., 2003).

The neural pathways involved in negative expectation have been elucidated via the placebo pain model. In analgesia studies, negative words and negative expectations trigger blocking of the opioid-mediated expectancy (Benedetti, 1996, Benedetti, 1997 and Benedetti et al., 1995) via cholecystokinin (CCK). It is specifically anticipatory anxiety ('anxiety which turns to pain') rather than generalised anxiety that is involved in the CCK component of hyperalgesia (Fig. 3). Whereas verbal suggestions of pain decrease activate endogenous opioids (Amanzio and Benedetti, 1999 and Zubieta et al., 2005) suggestions of pain increase activate CCK (Benedetti et al., 2006b). This negative expectation could also be invoked when the patient distrusts the medical personnel or methods involved (Barsky et al., 2002 and Flaten et al., 1991). In the arena of sports' medicine, where placebos can increase physical performance (Section 2.2.2), the use of negative suggestions coupled to a sham electrical stimulation have been shown to adversely affect physical performance (Pollo et al., 2012). The impact of negative words and expectations has also been investigated in Parkinson's disease. Here, patients with DBS electrode implants were told that the stimulator had been turned off, so as to induce negative expectations of motor worsening (Benedetti et al., 2003a). Motor performance worsened even though the stimulation was on (Benedetti et al., 2003a, Mercado et al., 2006 and Pollo et al., 2002). We have seen how opioid and dopamine release in the nucleus accumbens (NAC) have been found to be a direct measure of placebo response: high placebo 
Jubb, J., Bensing, J.M. The sweetest pill to swallow: how patient neurobiology can be harnessed to maximise placebo effects. Neuroscience and Biobehavioral Reviews: 2013, 37(10 Part 2), 2709-2720

responders show a greater increase in NAC opioid activity; likewise, in nocebo responders the NAC showed a deactivation in opioid release (Zubieta et al., 2005 and Zubieta et al., 2006).

\section{[FIGURE 3]}

Bingel et al. (2011) have shown, using fMRI, that positive expectancy doubled the analgesic benefit of opioid remifentanil whereas negative expectancy abolished its analgesic effects. In addition to the endogenous pain modulatory system (comprising the somatosensory cortex, cingulate cortex, insula, thalamus, and PAG), different brain pathways were activated with the differing expectancies: positive expectation showed enhanced activation in the anterior cingulate cortex and striatum, whereas negative expectations resulted in increased neural activity in the hippocampus, midcingulate cortex, and medial prefrontal cortex. Very recently, it has also been demonstrated that both nocebo and placebo mechanisms can be elicited by nonconscious triggers which operate outside conscious awareness (Jensen et al., 2012). In working with patients to maximise enhancing factors, it is important to be able to minimise the counter-productive effects, such as use of positive expectancypromoting vocabulary and soothing anticipatory anxiety. In this way, the practitioner can side-step the blocking of the opioid-mediated expectancy pathways, to be able to fully employ the positive expectancy, motivation and reward neurobiology. There is data showing that the announcement of painful interventions increases pain intensity (Lang et al., 2005), thus explaining too much to a patient may have detrimental effects by inducing anxious expectations. In general, making the patient aware in a positive manner of what is going on, why a certain procedure is being carried out and what positive results can be expected are all important factors in maximising the therapeutic outcome (Wells and Kaptchuk, 2012).

An important caveat here is that a functioning prefrontal cortex (PFC) is essential for expectancy in order to be able to initiate cognitive, top-down regulation. In placebo analgesia studies, Alzheimer's patients, in whom there is degeneration and disconnection of prefrontal lobes from the rest of the brain, show no placebo analgesic response (Benedetti, 2010 and Benedetti et al., 2006a). This was confirmed by temporarily disrupting the functioning of the DLPFC using rTMS in healthy subjects (Krummenacher et al., 2010). This interruption of the neural circuits blocked the placebo-induced analgesic effect completely. This implies that for interactionenhanced pharmacology to be successful in clinical practice a functioning prefrontal cortex is necessary, otherwise the expectancy-driven mechanisms are unlikely to function.

\section{EXTENDING INTERACTION-ENHANCED PHARMACOLOGY}

Interaction-enhanced pharmacology employs the patient-practitioner interaction to stimulate positive expectations and to diminish anxious expectations of adverse effects or treatment failure, using communication strategies as described in Section 2.1.1. It employs the patient's own neuropsychological system to enhance the efficacy of existing (drug) therapies. By moving the emphasis towards utilising the patient's own inherent capabilities, this rationale could also be extended within clinical practice to: 
Jubb, J., Bensing, J.M. The sweetest pill to swallow: how patient neurobiology can be harnessed to maximise placebo effects. Neuroscience and Biobehavioral Reviews: 2013, 37(10 Part 2), 2709-2720

- minimising side effects in treatments and therapies

- facilitating symptom relief

\subsection{Minimising side effects}

In medical terms, a side effect is defined as a secondary and usually adverse effect arising from a drug or treatment. One of the strengths of placebo effects is that they do seem to mimic the pharmacological pathways and effects that the drugs themselves elicit—and yet a placebo substance is by definition pharmacologically inert and contains no harmful substances.

In placebo analgesia studies, the placebo triggers the production of the patient's own endogenous opioids using opioid-mediated pathways and brain regions just like the verum analgesic to produce pain relief (Bingel et al., 2006, Bingel et al., 2011, Kong et al., 2006, Petrovic et al., 2002, Petrovic et al., 2005, Raz et al., 2005,Scott et al., 2008, Wager et al., 2004, Zubieta et al., 2005 and Zubieta et al., 2006). In Parkinson's disease, expectation and the reward of increased movement elicit dopamine release using the same nigrostriatal pathway as a potent anti-Parkinson and dopamine agonist apomorphine (Benedetti et al., 2009, de la Fuente-Fernández et al., 2001, Scott et al., 2008 and Strafella et al., 2006). The use of Pavlovian conditioning to produce physiological changes in the 'conditioned' immune system responses investigated by Goebel et al., 2002 and Goebel et al., 2005, showed that the effects of the conditioned stimulus were the same as those of the specific effects of immunosuppressant cyclosporine A, i.e. decrease in interleukin-2 (IL-2), interferon- $Y$ (IFN-y) and suppression of lymphocytes (T-cell function). In another clinical study by these same researchers (Goebel et al., 2009), a flavoured drink used as a conditioned stimulus resulted in the same reduction in basophil activation, histamine skin prick test and subjective symptom scores as the histamine (H1) receptor antagonist desloratadine in patients allergic to house-dust mites. It would appear therefore that use of placebos treatments would make drug-like effects possible, but without the drugs — and therefore without the side effects. However, just as placebos can mimic verum interventions they can also mimic their adverse effects. For example, patients in the placebo arm of clinical trials showed similar (adverse) side effects to the drug under investigation (Kaptchuk et al., 2006 and Amanzio et al., 2009). In Kaptchuk's 2006 study, even 'side effects' for sham acupuncture were observed.

In theory, the ideal way to use placebo effects would be to utilise the interactionenhanced pharmacology concept whereby the placebo mechanistic aspects are fully utilised, and yet tell the patient that they were getting a placebo (pill) in order to avoid any side effects due to their belief that they had been prescribed a verum pill. One of greatest obstacles to the use of placebos in clinical practice has been the belief that for placebos to be effective they must be administered deceptively. Kaptchuk et al. (2010) have recently reported the successful 'open-label' (no deception) administration of placebos for IBS, where patients were told that they 
Jubb, J., Bensing, J.M. The sweetest pill to swallow: how patient neurobiology can be harnessed to maximise placebo effects. Neuroscience and Biobehavioral Reviews: 2013, 37(10 Part 2), 2709-2720

would receive a placebo. The symptom relief patients reported was as large as that produced by commonly prescribed medication (alosetron) for IBS.

Since placebo's drug-mimicking properties trigger the patient's own 'internal pharmacy' this application could theoretically be useful whenever a drug has particularly noxious or unpleasant side effects (Ader et al., 2010,Greenberg and Roth, 1966, Kirsch et al., 2008, Olness and Ader, 1992 and Sandler et al., 2010). Whether or not the amount of verum medication can realistically be reduced by adding a placebo pill of the same appearance remains to be seen. However, extreme caution must be taken so as not to withhold a pharmacological therapy from a patient and thus endanger their health. It is preferable to utilise the interaction-enhanced pharmacology concept proposed here to enhance the effectiveness of the drug therapy.

\subsection{Facilitating symptom relief}

Since placebo and placebo effects are often linked to more psychosomatic ailments, it is not surprising that symptoms such as migraine (Bendtsen et al., 2003, Clayton et al., 2005, de Craen et al., 2000, Diener, 1999,Ferrari et al., 2001, Henry et al., 1995, Macedo et al., 2006 and Tfelt-Hansen et al., 1995), insomnia (Fratello et al., 2005, McCall et al., 2003 and Walsh et al., 2000), irritable bowel syndrome (Kaptchuk et al., 2009,Kelley et al., 2009, Vase et al., 2003, Vase et al., 2005 and Verne et al., 2003), gastric disturbances (Bernstein, 2006, Enck and Klosterhalfen, 2005 and Musial et al., 2007) and genitourinary disorders (Bradford and Meston, 2007, Fink et al., 2002, McConnell et al., 1998, Mondaini et al., 2007, Moyad, 2002,Nickel, 1998 and van Leeuwen et al., 2006) have been found to respond well to placebos. Most of the above disorders manifest themselves as painful conditions, and as we have seen, the mode of action of placebo - in addition to its effectiveness - in pain relief has been well established.

In the area of cancer, it seems that placebos can induce symptom reduction but not prevent cancer progression (Chvetzoff and Tannock, 2003). However, the importance of symptom reduction in cancer patients is not to be underestimated as cancer is increasingly being seen as a chronic illness rather than a quick and deadly disease. Much research is directed towards cancer prevention, diagnosis and cure, but there is a large chasm as far as living with cancer is concerned. In a very different non-pharmacological experimental approach, the effect of expectancy in chemotherapy-related nausea has been investigated using acupressure wrist bands (Roscoe et al., 2010). These had been found previously (Roscoe et al., 2003) to be effective in reducing nausea in subjects who expected them to be effective. (Patients who received the wrist bands and did not expect them to be effective experienced no difference in nausea). The patients' expectations were enhanced regarding the efficacy of the wrist bands by increasing the information available about the bands. Reduced nausea was experienced by patients who had high levels of expected nausea. 
Jubb, J., Bensing, J.M. The sweetest pill to swallow: how patient neurobiology can be harnessed to maximise placebo effects. Neuroscience and Biobehavioral Reviews: 2013, 37(10 Part 2), 2709-2720

\section{CLINICAL IMPLICATIONS: HOW PATIENT NEUROBIOLOGY CAN BE HARNESSED TO MAXIMISE PLACEBO EFFECTS}

This review has examined the neurobiological mechanisms underlying placebo effects and the different components capable of producing them. The concept of placebo is no longer simply confined to giving a fake pill to a difficult patient, but has grown to incorporate a broad range of psychosocial contexts that can be applied to medical care. This psychosocial context has its effect on patients every time clinicians interact with them, regardless of whether placebo or verum treatment is applied. In other words: placebo effects are inherent to every medical treatment and they have neurobiological implications that may affect patients' health and wellbeing. This evidence might thus be interpreted as an instigation (or even an ethical obligation) for doctors to use placebo effects for the benefit of the patient when providing care, and it even suggests that disregarding placebo effects might be suboptimal care. In itself, this idea is not new. Many doctors have always employed, and still do employ, methods to attain placebo effects as a matter of course (Bensing and Verheul, 2010, de Craen et al., 1999, Roberts et al., 1993 and Tilburt et al., 2008), but they often do so without conscious effort. The neurobiological explanations for placebo effects can help to determine how to set off patients' neurobiology for maximising placebo effects. This review shows that probably the most potent method for doing so lies in the doctor-patient interaction (Bensing and Verheul, 2010, Di Blasi et al., 2001,Kaptchuk et al., 2009 and Van Dulmen and Bensing, 2001). Although more research is needed in this area, some directions can be outlined as to how the patients' neurobiological pathways might be activated by doctors' (or nurses') targeted communication, and in particular with reference to the opioidergic and the dopaminergic pathways.

Opioidergic activation is triggered by patients' expectations. The major components that are needed to attain positive expectations are that the practitioner has to state that positive effects of a treatment can be expected, in a clear and unambiguous way. Secondly the patient has to believe the message delivered, and for this, a good therapeutic relationship between practitioner and patient is important. There is ample evidence that a good relationship is significantly determined by a practitioner's affective communication style: warmth, eye contact, active listening, empathy, thoughtful silences, and leaving room for the patient to tell their story are of pivotal importance here (Epstein and Street, 2007, Roter and Hall, 2006 and Stewart, 1995). Perhaps unsurprisingly, the combination of enhancing expectation and communicating in a warm and empathic way seems to have the best effects in increasing patients' expectations (Verheul et al., 2010). Although dopaminergic activations are similarly triggered by expectations, these are foremostly generated in placebo effects when there is a reward aspect present (e.g. the reward of diminished pain). Several studies (Walter et al., 2005 for an overview) also show that cooperative social interaction activated the reward circuitry, whereas noncooperative behaviour did not do so. This again points to practitioners' affective communication style as a way to harnessing placebo effects. It should be noted that studies directlyassessing patients' neurobiology when trying to elicit placebo effects 
Jubb, J., Bensing, J.M. The sweetest pill to swallow: how patient neurobiology can be harnessed to maximise placebo effects. Neuroscience and Biobehavioral Reviews: 2013, 37(10 Part 2), 2709-2720

in response to different kinds of practitioner communication are still missing and very much needed (Bensing and Verheul, 2010). Measuring the release of opioids and dopamine in patients whilst they are being exposed to different styles of doctorpatient communication (e.g. via video vignettes) seems a promising next step in this line of research.

\section{CONCLUSION}

Traditionally, the placebo effect has often been referred to in a derogatory, denigrating way as some sort of unwanted effect that would be better ignored than worthy of scientific investigation. In the light of modern day pharmacology it tends to be easily forgotten that recovery entails more than just pharmacological drug action. That the external trigger can be a pill, injection, surgery or the 'right' words or demeanour at the right time from a practitioner is a reminder that it is the patient, and not the doctor, who in the end is the real agent to recovery. The stimulus that the placebo provides, by raising expectancies embedded in a warm and empathic doctorpatient relationship, appears to stimulate the internal pharmacy that humans seem to possess. Over the last 15 years neuroscience has started to provide a scientifically satisfying method to investigate how, where and when these intriguing effects occur.

So rather than writing them off as 'just the placebo effect', we need to fully appreciate how much that 'just' contains - and to start utilising and applying it in clinical practice. It is by being able to consciously tap into the neurobiology of the patient's own brain, and thus collaborating with their entire psychophysiological system, which could truly revolutionise modern medicine. It is this that could be the sweetest (placebo) pill we have yet to swallow.

\section{CONFLICT OF INTEREST}

The authors have no conflicts of interest.

\section{ACKNOWLEDGEMENTS}

This study was funded by the Spinoza Prize awarded to Professor Jozien Bensing, PhD by the Dutch Research Council (NWO).

\section{APPEndix A.}

Keywords, or combinations of keywords, used for the literature search were: placebo effect mechanism, placebo effect brain, placebo effect neuroscience, placebo effect neurobiology, placebo effect neurobiological mechanisms, placebo effect neural mechanisms, placebo effect neural correlates, placebo effect biological mechanisms, placebo effect biological models, placebo effect biochemical, placebo effect understanding, placebo effect review, placebo effect classical conditioning, placebo effect neurotransmitter, placebo effect dopamine, placebo effect dopamine pathway, placebo effect serotonin, placebo effect reward, placebo effect motivation, placebo effect non-specific, placebo effect expectation placebo response mechanism, placebo response brain, placebo response neuroscience, placebo response neurobiology, placebo response neurobiological mechanisms, placebo response neural mechanisms, placebo response neural correlates, placebo response biological mechanisms, placebo response biological 
Jubb, J., Bensing, J.M. The sweetest pill to swallow: how patient neurobiology can be harnessed to maximise placebo effects. Neuroscience and Biobehavioral Reviews: 2013, 37(10 Part 2), 2709-2720

models, placebo response biochemical, placebo response understanding, placebo response review, placebo response classical conditioning, placebo effect neurotransmitter, placebo response dopamine, placebo response dopamine pathway, placebo response serotonin, placebo response reward, placebo response motivation, placebo response non-specific, placebo response expectation placebo effect pain, placebo effect analgesia, placebo effect Parkinsons, placebo effect depression, placebo effect Alzheimer, placebo effect dementia, placebo effect schizophrenia, placebo effect addiction, placebo effect sham surgery, placebo effect migraine, placebo effect deep brain stimulation placebo response pain, placebo response analgesia, placebo response Parkinsons, placebo response depression, placebo response Alzheimer, placebo response dementia, placebo response schizophrenia, placebo response addiction, placebo response sham surgery, placebo response migraine, placebo response deep brain stimulation

\section{REFERENCES}

Ader et al., 2010 R. Ader, M.G. Mercurio, J. Walton, D. James, M. Davis, V. Ojha, A.B. Kimball, D. Fiorentino Conditioned pharmacotherapeutic effects: a preliminary study Psychosom. Med., 72 (2010), pp. 192-197

Amanzio and Benedetti, 1999 M. Amanzio, F. Benedetti Neuropharmacological dissection of placebo analgesia: expectation-activated opioid systems versus conditioning-activated specific subsystems J. Neurosci., 19 (1999), pp. 484-494

Amanzio et al., 2001 M. Amanzio, A. Pollo, G. Maggi, F. Benedetti Response variability to analgesics: a role for non-specific activation of endogenous opioids Pain, 90 (2001), pp. 205-215

Amanzio et al., 2009 M. Amanzio, L.L. Corazzini, L. Vase, F. Benedetti

A systematic review of adverse events in placebo groups of anti-migraine clinical trials Pain, 146 (2009), pp. 261-269

Andrews, $2001 \mathrm{G}$. Andrews Placebo response in depression: Bane of research, boon to therapy Br. J. Psychiatry, 178 (2001), pp. 192-194

Andrykowski and Otis, 1990 M.A. Andrykowski, M.L. Otis

Development of learned food aversions in humans: investigation in a 'natural laboratory' of cancer chemotherapy Appetite, 14 (1990), pp. 145-158

Balint, 1957 M. Balint The Doctor: His Patient and The Illness Tavistock Publications, London (1957)

Barrett et al., 2007 B. Barrett, D. Rakel, B. Chewning, L. Marchand, D. Rabago, R. Brown et al. Rationale and methods for a trial assessing placebo, echinacea, and doctor-patient interaction in the common cold Explore, 6 (2007), p. 561

Barsky et al., 2002 A.J. Barsky, R. Saintfort, M.O. Rogers, J.F. Borus Nonspecific medication side effects and the nocebo phenomeno JAMA, 287 (2002), pp. 622-627

Bass et al., 1986 M.J. Bass, C. Buck, L. Turner, G. Dickie, G. Pratt, H.C. Robinson The physician's actions and the outcome of illness in family practice J. Family Practice, 23 (1986), pp. 43-47

Batterman, 1966 R.C. Batterman Persistence of responsiveness with placebo therapy following an effective drug trial J. Clin. Pharmacol., 6 (3) (1966), pp. 137-141

Batterman and Lower, 1968 R.C. Batterman, W.R. Lower Placebo responsiveness-influence of previous therapy Curr. Therap. Res. Clin. Exp., 10 (1968), pp. 136-143 
Jubb, J., Bensing, J.M. The sweetest pill to swallow: how patient neurobiology can be harnessed to maximise placebo effects. Neuroscience and Biobehavioral Reviews: 2013, 37(10 Part 2), 2709-2720

Beecher, 1955 H.K. Beecher The powerful placebo JAMA, 159 (1955), pp. 1602-1606

Bendtsen et al., 2003 L. Bendtsen, P. Mattsson, J.A. Zwart, R.B. Lipton Placebo response in clinical randomized trials of analgesics in migraine Cephalagia, 23 (2003), pp. 487-490

Benedetti, 1996 . Benedetti The opposite effects of the opiate antagonist naloxone and the cholecystokinin antagonist proglumide on placebo analgesia Pain, 64 (1996), pp. 535-543

Benedetti, 1997 F. Benedetti Cholecystokinin type-A and type-B receptors and their modulation of opioid analgesia News Physiol. Sci., 12 (1997), pp. 263-268

Benedetti, 2010 F. Benedetti No prefrontal control, no placebo response Pain, 148 (2010), pp. 357-358

Benedetti et al., $1995 \mathrm{~F}$. Benedetti, M. Amanzio, G. Maggi Potentiation of placebo analgesia by proglumide Lancet, 346 (1995), p. 1231

Benedetti et al., 1999 F. Benedetti, C. Arduino, M. Amanzio Somatotopic activation of opioid systems by target-directed expectations of analgesia J. Neurosci., 19 (9) (1999), pp. 3639 3648

Benedetti et al., 2003a F. Benedetti, A. Pollo, L. Lopiano, M. Lanotte, S. Vighetti, I. Rainero Conscious expectation and unconscious conditioning in analgesic, motor, and hormonal placebo/nocebo responses J. Neurosci., 23 (2003), pp. 4315-4323

Benedetti et al., 2003b F. Benedetti, G. Maggi, L. Lopiano, M. Lanotte, I. Rainero, S. Vighetti et al. Open versus hidden medical treatments: The patient's knowledge about a therapy affects the therapy outcome Prev. Treat., 6 (1) (2003)

Benedetti et al., 2004a F. Benedetti, L. Colloca, E. Torre, M. Lanotte, A. Melcarne, M. Pesare et al. Placebo-responsive Parkinson patients show decreased activity in single neurons of subthalamic nucleus Nat. Neurosci., 7 (2004), pp. 587-588

Benedetti et al., 2004b F. Benedetti, L. Colloca, M. Lanotte, B. Bergamasco, E. Torre, L. Lopiano Autonomic and emotional responses to open and hidden stimulations of the human subthalamic region Brain Res. Bull., 63 (2004), pp. 203-211

Benedetti et al., 2005 F. Benedetti, H.S. Mayberg, T.D. Wager, C.S. Stohler, J. Zubieta Neurobiological mechanisms of the placebo effect J. Neurosci., 25 (2005), pp. 1039010402

Benedetti et al., 2006a F. Benedetti, C. Arduino, S. Costa, S. Vighetti, L. Tarenzi, I. Rainero et al. Loss of expectation-related mechanisms in Alzheimer's disease makes analgesic therapies less effective Pain, 121 (2006), pp. 133-144

Benedetti et al., 2006b F. Benedetti, M. Amanzio, S. Vighetti, G. Asteggiano The biochemical and neuroendocrine bases of the hyperalgesic nocebo effect

J. Neurosci., 26 (2006), pp. 12014-12022

Benedetti et al., 2007a F. Benedetti, M. Lanotte, L. Lopiano, L. Colloca When words are painful—unraveling the mechanisms of the nocebo effect Neuroscience, 147 (2007), pp. 260-271

Benedetti et al., 2007b F. Benedetti, A. Pollo, L. Colloca Opioid-mediated placebo responses boost pain endurance and physical performance: is it doping in sport competitions $\mathrm{J}$.

Neurosci., 23 (2007), pp. 4315-4323

Benedetti et al., 2009 F. Benedetti, M. Lanotte, L. Colloca, A. Ducati, M. Zibetti, L. Lopiano Electrophysiological properties of thalamic, subthalamic and nigral neurons during the antiparkinsonian placebo response J. Physiol., 587 (2009), pp. 3869-3883

Benedetti et al., 2011 F. Benedetti, M. Amanzio, R. Rosato, C. Blanchard Nonopioid placebo analgesia is mediated by CB1 cannabinoid receptors Nat. Med., 17 (2011), pp. 1228-1230 Bensing and Dronkers, 1992 J.M. Bensing, J. Dronkers Instrumental and affective aspects of physician behavior Med. Care, 30 (1992), pp. 283-297 
Jubb, J., Bensing, J.M. The sweetest pill to swallow: how patient neurobiology can be harnessed to maximise placebo effects. Neuroscience and Biobehavioral Reviews: 2013, 37(10 Part 2), 2709-2720

Bensing et al., 1996 J.M. Bensing, K. Schreurs, A. de Rijk The role of physician's affective behaviour in medical encounters Psychol. Health, 11 (1996), pp. 825-838

Bensing and Verheul, 2010 J.M. Bensing, W. Verheul The silent healer: The role of communication in placebo effects Patient Educ. Couns., 80 (2010), pp. 293-299

Berger, 1999 J.T. Berger Placebo medication use in patient care: a survey of medical interns West. J. Med., 170 (2) (1999), pp. 93-96

Bernstein, 1991 I.L. Bernstein Aversion conditioning in response to cancer and cancer treatment Clin. Psych. Revs., 11 (1991), pp. 185-191

Bernstein, 2006 C.N. Bernstein The placebo effect for gastroenterology: tool or torment Clin. Gastroenterol. Hepatol., 4 (2006), pp. 1302-1308

Bingel et al., 2006 U. Bingel, J. Lorenz, E. Schoell, C. Weiller, C. Buchel Mechanisms of placebo analgesia: rACC recruitment of a subcortical antinociceptive network Pain, 120 (2006), pp. 8-15

Bingel et al., 2011 U. Bingel, V. Wanigasekera, K. Wiech, R.N. Mhuircheartaigh, M.C. Lee, M. Ploner, I. Tracey The effect of treatment expectation on drug efficacy: imaging the analgesic benefit of the opioid remifentanil Sci. Trans. Med., 3 (2011) 70ra14

Bradford and Meston, 2007 A. Bradford, C. Meston Correlates of placebo response in the treatment of sexual dysfunction in women: a preliminary report J. Sex. Med., 4 (2007), pp. 1345-1351

Branthwaite and Cooper, 1981 A. Branthwaite, P. Cooper Analgesic effects of branding in treatment of headaches Br. Med. J. (Clin. Res. Ed.), 282 (6276) (1981), pp. 1576-1578

Breton et al., 2008 J.D. Breton, P. Veinante, S. Uhl-Bronner, A.M. Vergnano, M.J. FreundMercier, R. Schlichter et al. Oxytocin-induced antinociception in the spinal cord is mediated by a subpopulation of glutamatergic neurons in lamina I-II which amplify GABAergic inhibition Mol. Pain, 4 (2008), p. 19

Brody, $1997 \mathrm{H}$. Brody The doctor as therapeutic agent: a placebo effect research agenda A. Harrington (Ed.), The Placebo Effect: An Interdisciplinary Exploration, Harvard University Press, Cambridge, MA (1997), pp. 77-92

Brody, $2009 \mathrm{H}$. Brody Medicine's continuing quest for an excuse to avoid relationships with patients Am. J. Bioeth., 9 (2009), pp. 13-15

Brunoni et al., 2009 A.R. Brunoni, M. Lopes, T.J. Kaptchuk, F. Fregni Placebo response of non-pharmacological and pharmacological trials in major depression: a systematic review and meta-analysis PLoS ONE, 4 (2009), p. e4824

Buckalew and Ross, 1981 L.W. Buckalew, S. Ross Relationship of perceptual characteristics to efficacy of placebos Psychol. Rep., 49 (3) (1981), pp. 955-961

Chvetzoff and Tannock, 2003 G. Chvetzoff, I.F. Tannock Placebo effects in oncology

J. Nat. Cancer Inst., 95 (2003), pp. 19-29

Clayton et al., 2005 A.H. Clayton, S.G. West, E. McGarvery, C. Leslie, A. Keller Biochemical evidence of the placebo effect during the treatment of menstrual migraines $\mathrm{J}$. Clin.

Psychopharmacol., 25 (2005), pp. 400-401

Cobb et al., 1959 L.A. Cobb, G.I. Thomas, D.H. Dillard, K.A. Merendino, R.A. Bruce An evaluation of internal mammary artery ligation by double-blind technique New Eng. J. Med., 260 (1959), pp. 1115-1118

Colloca et al., 2004 L. Colloca, L. Lopiano, M. Lanotte, F. Benedetti Overt versus covert treatment for pain, anxiety, and Parkinson's disease Lancet Neurol., 3 (2004), pp. 679-684 Colloca and Benedetti, 2005 L. Colloca, F. Benedetti Placebos and painkillers: is mind as real as matter? Nat. Rev. Neurosci., 6 (2005), pp. 545-552

Colloca and Benedetti, 2006 L. Colloca, F. Benedetti How prior experience shapes placebo analgesia Pain, 124 (2006), pp. 126-133 
Jubb, J., Bensing, J.M. The sweetest pill to swallow: how patient neurobiology can be harnessed to maximise placebo effects. Neuroscience and Biobehavioral Reviews: 2013, 37(10 Part 2), 2709-2720

Crow et al., 1999 R. Crow, H. Gage, S. Hampson, J. Hart, A. Kimber, H. Thomas The role of expectancies in the placebo effect and their use in the delivery of health care: A systematic review Health Technol. Assess., 3 (3) (1999), pp. 1-96

de Craen et al., 1996 A.J. de Craen, P.J. Roos, A. Leonard de Vries, J. Kleijnen Effect of colour of drugs: systematic review of perceived effect of drugs and of their effectiveness BMJ, 313 (7072) (1996), pp. 1624-1626

de Craen et al., 1999 A.J. de Craen, T.J. Kaptchuk, J.G. Tijssen, J. Kleijnen Placebos and placebo effects in medicine: historical overview J. R. Soc. Med., 92 (10) (1999), pp. 511515

de Craen et al., 2000 A.J.M. de Craen, J.G.P. Tijssen, J. de Gans, J. Kleijnen Placebo effect in the acute treatment of migraine: subcutaneous placebos are better than oral placebos $\mathrm{J}$. Neurol., 247 (2000), pp. 183-188

de Haes and Bensing, 2009 H. de Haes, J.M. Bensing Endpoints in medical communication research, proposing a framework of functions and outcomes Patient Educ. Couns., 74 (3) (2009), pp. 287-294

de la Fuente-Fernández et al., 2001 R. de la Fuente-Fernández, T.J. Ruth, V. Sossi, M. Schulzer, D.B. Calne, A.J. Stoessl Expectation and dopamine release: mechanism of the placebo effect in Parkinson's disease Science, 293 (2001), pp. 1164-1166

de la Fuente-Fernández et al., 2002 R. de la Fuente-Fernández, A.G. Phillips, M. Zamburlini, V. Sossi, D.B. Calne, T.J. Ruth et al. Dopamine release in human ventral striatum and expectation of reward Behav. Brain Res., 136 (2002), pp. 359-363

de la Fuente-Fernandez and Stoessl, 2002 R. de la Fuente-Fernandez, A.J. Stoessl The placebo effect in Parkinson's disease Trends Neurosci., 25 (2002), pp. 302-306

de la Fuente-Fernandez et al., 2004 R. de la Fuente-Fernandez, M. Schulzer, A.J. Stoessl Placebo mechanisms and reward circuitry: clues from parkinson's disease Biol. Psychiatry, 56 (2004), pp. 67-71

Di Blasi et al., 2001 Z. Di Blasi, E. Harkness, E. Ernst, A. Georgiu, J. Kleijnen Influence of context effects on health outcomes: a systematic review Lancet, 357 (2001), pp. 757-762

Diener, 1999 H.C. Diener Effcacy and safety of intravenous acetylsalicyclic acid lysinate compared to subcutaneous sumatripan and parenteral placebo in the acute treatment of migraine. A double-blind, double dummy, randomized, multicenter, parallel group study. The ASASUMAMIG Study Group Cephalagia, 19 (1999), pp. 581-588

Dimond et al., 1958 E.G. Dimond, C.F. Kittle, J.E. Crockett Evaluation of internal mammary ligation and sham procedure in angina pectoris Circulation, 18 (1958), pp. 712-713

Enck and Klosterhalfen, 2005 P. Enck, S. Klosterhalfen The placebo response in functional bowel disorders: perspectives and putative mechanisms Neurogastroenterol. Motil., 17 (2005), pp. 325-331

Enck and Klosterhalfen, 2009 P. Enck, S. Klosterhalfen The story of O-is oxytocin the mediator of the placebo response? Neurogastroenterol. Motil., 21 (2009), pp. 347-350

Engel, 1988 G.L. Engel How much longer must medicine's science be bound by a seventeenth century world view K. White (Ed.), The Task of Medicine: Dialogue at Wickenburg, The Henry Kaiser Foundation, Menlo Park, USA (1988), pp. 113-136 Epstein and Street, 2007 Epstein, R.M., Street, R.L.J., 2007. Patient-centered communication in cancer care:promoting healing and reducing suffering. NIH Publication No. 07-6225.

Ferrari et al., 2001 M.D. Ferrari, K.I. Roon, R.B. Lipton, P.J. Goadsby Oral triptans (serotonin 5-HT 1B/1D agonists) in acute migraine treatment: a meta-analysis of 53 trials Lancet, 358 (2001), pp. 1668-1675 
Jubb, J., Bensing, J.M. The sweetest pill to swallow: how patient neurobiology can be harnessed to maximise placebo effects. Neuroscience and Biobehavioral Reviews: 2013, 37(10 Part 2), 2709-2720

Fink et al., 2002 H.A. Fink, R. MacDonald, I.R. Rutks, D.B. Nelson, T.J. Wilt Sildenafil for male erectile dysfunction: a systematic review and meta-analysis Arch. Intern. Med., 162 (2002), pp. 1349-1360

Finniss and Benedetti, 2005 D.G. Finniss, F. Benedetti Mechanisms of the placebo response and their impact on clinical trials and clinical practice Pain, 114 (2005), pp. 3-6

Finniss et al., 2010 D.G. Finniss, T.J. Kaptchuk, F. Miller, F. Benedetti Biological, clinical, and ethical advances of placebo effects Lancet, 375 (2010), pp. 686-695

Flaten et al., 1991 M.A. Flaten, T. Simonsen, H. Olsen Mechanisms of the placebo response and their impact on clinical trials and clinical practice Pain, 114 (1991), pp. 3-6

Fowler, 2007 C.J. Fowler The contribution of cyclooxygenase-2 to endocannabinoid metabolism and action Br. J. Pharmacol., 152 (2007), pp. 594-601

Fratello et al., 2005 F. Fratello, G. Curcio, M. Ferrara, C. Marzano, A. Couyoumdjian, G. Petrillo et al. Can an inert sleeping pill affect sleep? Effects on polysomnographic, behavioural and subjective measures Psychopharmacology, 181 (2005), pp. 761-770

Freed et al., 2001 C.R. Freed, P.E. Greene, R.E. Breeze, W.Y. Tsai, W. DuMouchel, R. Kao et al. Transplantation of embryonic dopamine neurons for severe Parkinson's disease N. Engl. J. Med., 344 (2001), pp. 710-719

Fricchione and Stefano, 2005 G. Fricchione, G.B. Stefano Placebo neural systems: nitric oxide, morphine and the dopamine brain reward and motivation circuitries

Med. Sci. Monit., 11 (2005), pp. MS54-MS65

Garris et al., 1999

P.A. Garris, M. Kilpatrick, M.A. Bunin, D. Michael, Q.D. Walker, R.M. Wightman

Dissociation of dopamine release in the nucleus accumbens from intracranial self-stimulation Nature, 398 (1999), pp. 67-69

Geuter et al., 2013 S. Geuter, F. Eippert, C. Hindi Attar, C. Buchel Cortical and subcortical responses to high and low effective placebo treatments Neuroimage, 67 (2013), pp. 227236

Goebel et al., 2002 M.U. Goebel, A.E. Trebst, J. Steiner, Y.F. Xie, M.S. Exton, S. Frede et al. Behavioural conditioning of immunosuppression is possible in humans FASEB J., 16 (2002), pp. 1869-1873

Goebel et al., 2005 M.U. Goebel, D. Hubell, W. Kou, O.E. Janssen, Z. Katsarava, V. immroth et al. Behavioural conditioning with interferon beta-1a in humans Physiol. Behav., 84 (2005), pp. 807-814

Goebel et al., 2009 M.U. Goebel, N. Meykadeh, W. Kou, M. Schedlowski, U.R. Hengge Behavioural conditioning of antihistamine effects in patients with allergic rhinitis Psychother. Psychosom., 77 (2009), pp. 227-234

Goetz et al., 2000 C.G. Goetz, S. Leurgans, R. Raman, G.T. Stebbins Objective changes in motor function during placebo treatment in PD Neurology, 54 (2000), p. 710

Gracely et al., 1983 R.H. Gracely, R. Dubner, P.J. Wolskee, W.R. Deeter Placebo and naloxone can alter post-surgical pain by separate mechanisms Nature, 306 (1983), pp. 264-265

Greenberg and Roth, 1966 L.M. Greenberg, S. Roth Differential effects of abrupt versus gradual withdrawal of chlorpromazine in hospitallized chronic schizophrenic patients Am. J. Psychol., 123 (1966), pp. 221-226

Greenfield et al., 1985 S. Greenfield, S. Kaplan, J.E. Ware Expanding patient involvement in care Ann. Intern. Med., 102 (1985), pp. 520-528

Grevert et al., 1983 P. Grevert, L. Albert, A. Goldstein Partial antagonism of placebo analgesia by naloxone Pain, 16 (1983), pp. 129-143 
Jubb, J., Bensing, J.M. The sweetest pill to swallow: how patient neurobiology can be harnessed to maximise placebo effects. Neuroscience and Biobehavioral Reviews: 2013, 37(10 Part 2), 2709-2720

Henry et al., 1995 P. Henry, O. Hiesse-Provost, A. Dillenschneider, H. Ganry, J. Insuasty Efficacy and tolerance of an effervescent aspirin-metoclopramide combination in the treatment of a migraine attack. Randomized double-blind study using a placebo Presse Med., 24 (5) (1995), pp. 254-258

Hrobjartsson and Gøtzsche, 2001 A. Hrobjartsson, P.C. Gøtzsche Is the placebo effect powerless? An analysis of clinical trials comparing placebo with no treatment $\mathrm{N}$. Engl. J. Med., 344 (2001), pp. 1594-1602

Hrobjartsson and Norup, 2003 A. Hrobjartsson, M. Norup The use of placebo interventions in medical practice - A national questionnaire survey of Danish clinicians Eval. Health Prof., 26 (2) (2003), pp. 153-165

Hrobjartsson and Gøtzsche, 2004a A. Hrobjartsson, P.C. Gøtzsche Is the placebo effect powerless? Update of a systematic review with 52 new randomized trials comparing placebo with no treatment J. Int. Med., 256 (2004), pp. 91-100

Hrobjartsson and Gøtzsche, 2004b Hrobjartsson, A., Gøtzsche, P.C., 2004b. Placebo interventions for all clinical conditions. Cochrane Database of Systematic Reviews Issue 2 Art No: CD003974. Hrobjartsson and Gøtzsche, 2006 A. Hrobjartsson, P.C. Gøtzsche Unsubstantiated claims of large effects of placebo on pain: serious errors in meta-analysis of placebo analgesia mechanism studies J. Clin. Epidemiol., 59 (2006), pp. 336-338

Hrobjartsson and Gøtzsche, 2007a Hrobjartsson, Gøtzsche Powerful spin in the conclusion of Wampold et al's re-analysis of placebo versus no-treatment trials despite similar results as in original review J. Clin. Psychol., 63 (4) (2007), pp. 373-377

Hrobjartsson and Gøtzsche, 2007b A. Hrobjartsson, P.C. Gøtzsche Wampold et al's reiterate spin in the conclusion of a re-analysis of placebo versus no-treatment trials despite similar results as in original review J. Clin. Psychol., 63 (4) (2007), pp. 405-408

Hrobjartsson and Gøtzsche, 2010 Hrobjartsson, A., Gøtzsche, P.C., 2010. Placebo interventions for all clinical conditions. Cochrane Database of Systematic Reviews Issue 1 Art No: CD003974.

Hróbjartsson et al., 2011 A. Hróbjartsson, T.J. Kaptchuk, F.G. Miller Placebo effect studies are susceptible to response bias and to other types of biases J. Clin. Epidemiol., 64 (2011), pp. 1223-12239

Husten, 1999 . Husten Fetal-cell-implantation trial yields mixed results Lancet, 353 (1999), p. 1501

Jacobsen et al., 1993 P.B. Jacobsen, D.H. Bovbjerg, M.D. Schwartz, M.A. Andrykowskim, A.D. Futterman, T. Gilewski et al. Formation of food aversions in cancer patients receiving repeated infusions of chemotherapy Behav. Res. Ther., 31 (1993), pp. 739-748

Jensen et al., 2012 K.B. Jensen, T.J. Kaptchuk, I. Kirsch, J. Raicek, K.M. Lindstrome, C. Berna, R.L. Gollub, M. Ingvare, J. Kong Nonconscious activation of placebo and nocebo responses PNAS, 109 (2012), pp. 15959-15964

Jensen et al., 2013 K.B. Jensen, P. Petrovic, C. Kerr, I. Kirsch, J. Raicek, A. Cheetham, R. Spaeth, A. Cook, R.L. Gollub, J. Kong, T.J. Kaptchuk Sharing pain and relief: neural correlates of physicians during treatment of patients Mol. Psychol. (2013) doi: $10.1038 / \mathrm{mp} .2012 .195$

Kaptchuk, 1998 T. Kaptchuk Powerful placebo: The dark-side of the randomized controlled trial Lancet, 351 (1998), p. 1722

Kaptchuk et al., 2000 T.J. Kaptchuk, P. Goldman, D.A. Stone, W.B. Stason Do medical devices have enhanced placebo effects? J. Clin. Epidemiol., 53 (2000), pp. 786-792

Kaptchuk et al., 2006 T.J. Kaptchuk, W.B. Stason, R.B. Davis, A.R. Legedza, R.N. Schnyer, C.E. Kerr et al. Sham device $v$ inert pill: randomised controlled trial of two placebo treatments BMJ, 332 (2006), pp. 391-397 
Jubb, J., Bensing, J.M. The sweetest pill to swallow: how patient neurobiology can be harnessed to maximise placebo effects. Neuroscience and Biobehavioral Reviews: 2013, 37(10 Part 2), 2709-2720

Kaptchuk et al., 2009 T.J. Kaptchuk, J. Shaw, C.E. Kerr, L.A. Conboy, J.M. Kelley, T.J. Csordas et al. Maybe i made up the whole thing": placebos and patients' experiences in a randomized controlled trial Cult. Med. Psychiatry, 33 (2009), pp. 382-411

Kaptchuk et al., 2010 T.J. Kaptchuk, E. Friedlander, J.M. Kelley, M.N. Sanchez, E. Kokkotou, J.P. Singer, M. Kowalczykowski, F.G. Miller, I. Kirsch, A.J. Lembo Placebos without deception: a randomized controlled trial in irritable bowel syndrome PLoS One, 5 (2010), p. e15591

Kelley and Berridge, 2002 A.E. Kelley, K.C. Berridge The neuroscience of natural rewards: relevance to addictive drugs J. Neurosci., 22 (2002), pp. 3306-3311

Kelley et al., 2009 J.M. Kelley, A.J. Lembo, J.S. Ablon, J.J. Villanueva, L.A. Conboy, R. Levy et al. Patient and practitioner influences on the placebo effect in irritable bowel syndrome Psychosom. Med., 71 (2009), pp. 789-797

Khan et al., 2000 A. Khan, H.A. Warner, W.A. Brown Symptom reduction and suicide risk in patients treated with placebo in antidepressant clinical trials: An analysis of the FDA database Arch. Gen. Psychiatry, 57 (2000), pp. 311-317

Kirsch, $1985 \mathrm{I}$. Kirsch Response expectancy as a determinant of experience and behavior Am. Psychol., 40 (1985), pp. 1189-1202

Kirsch, $2004 \mathrm{I}$. Kirsch Conditioning, expectancy, and the placebo effect: comment on Stewart-Williams and Pod Psychol. Bull., 130 (2) (2004), pp. 341-342

Kirsch et al., 2008 I. Kirsch, B.J. Deacon, T.B. Huedo-Medina, A. Scoboria, T.J. Moore, B.T. Johnson Initial severity and antidepressant benefits: a meta-analysis of data submitted to the Food and Drug Administration PLoS Med., 5 (2008), p. e45

Klosterhalfen et al., 2005 S. Klosterhalfen, S. Kelerman, U. Stockhorst, J. Wolf, C. Kirschbaum, G. Hallet al. Latent inhibition of rotation chair-induced nausea in healthy male and female volunteers Psychosom. Med., 67 (2) (2005), pp. 335-340

Kong et al., 2006 J. Kong, R.L. Gollub, I.S. Rosman, J.M. Webb, M.G. Vangelm, I. Kirsch et al. Brain activity associated with expectancy-enhanced placebo analgesia as measured by functional magnetic resonance imaging J. Neurosci., 26 (2006), pp. 381-388

Krummenacher et al., 2010 P. Krummenacher, V. Candia, G. Folkers, M. Schedlowski, G. Schönbächler Prefrontal cortex modulates placebo analgesia Pain, 148 (2010), pp. 368374

Lang et al., 2005 E.V. Lang, O. Hatsiopoulou, T. Koch, K. Berbaum, S. Lutgendorf et al. Can words hurt? Patient-provider interactions during invasive procedures Pain, 114 (2005), pp. 303-309

Lanotte et al., 2005 M. Lanotte, L. Lopiano, E. Torre, B. Bergamasco, L. Colloca, F. Benedetti Expectation enhances autonomic responses to stimulation of the human subthalamic limbic region Brain Behav. Immun., 19 (2005), pp. 500-509

Laska and Sunshine, 1973 E. Laska, A. Sunshine Anticipation of analgesia: a placebo effect Headache, 13 (1973), pp. 1-11

Last, 1983 J.M. Last Dictionary of Epidemiology Oxford University Press, New York (1983) Leuchter et al., 2002 A.F. Leuchter, I.A. Cook, E.A. Witte, M. Morgan, M. Abrams Changes in brain function of depressed subjects during treatment with placebo Am. J. Psychiatry, 159 (2002), pp. 122-129

Levine et al., 1978 J.D. Levine, N. Gordon, H. Fields The mechanism of placebo analgesia Lancet, 2 (1978), pp. 654-657

Levine et al., 1981 J.D. Levine, N.C. Gordon, R. Smith, H.L. Fields Analgesic response to morphine and placebo individuals with postoperative pain Pain, 10 (1981), pp. 379-389

Levine and Gordon, 1984 J.D. Levine, N.C. Gordon Influence of the method of drug administration on analgesic response Nature, 312 (1984), pp. 755-756 
Jubb, J., Bensing, J.M. The sweetest pill to swallow: how patient neurobiology can be harnessed to maximise placebo effects. Neuroscience and Biobehavioral Reviews: 2013, 37(10 Part 2), 2709-2720

Lichko, 1959 A.E. Lichko Conditioned reflex hypoglycemia in man Pavlov. J. High Nerv. Activity, 9 (1959), pp. 731-737

Macedo et al., 2006 A. Macedo, M. Farre, J.E. Banos A meta-analysis if the placebo response in acute migraine and how this response may be influenced by some of the characteristics of clinical trials Eur. J. Clin. Pharmacol., 62 (2006), pp. 161-172

Mayberg et al., 2002 H.S. Mayberg, J.A. Silva, S.K. Brannan, J.L. Tekell, R.K. Mahurin, S. McGinnis et al. The functional neuroanatomy of the placebo effect Am. J. Psychiatry, 159 (2002), pp. 728-737

McCall et al., 2003 W.V. McCall, R. D’Agostino Jr., A. Dunn A meta-analysis of sleep changes associated with placebo in hypnotic clinical trials Sleep Med., 4 (2003), pp. 57-62

McConnell et al., 1998 J.D. McConnell, R. Bruskewitz, P. Walsh, G. Andriole, M. Lieber, H.L. Holtgreweet al. The effects of finasteride on the risk of acute urinary retention and the need for surgical treatment among men with benign prostatic hyperplasia. Finasteride long-term efficacy and safety study group New Eng. J. Med., 338 (1998), pp. 557-563

McRae et al., 2004 C. McRae, E. Cherin, T.G. Yamazaki, G. Diem, A.H. Vo, D. Russell et al. Effects of perceived treatment on quality of life and medical outcomes in a double-blind placebo surgery trial Arch. Gen. Psychiatry, 61 (2004), pp. 412-420

Mercado et al., 2006 R. Mercado, C. Constantoyannis, T. Mandat, A. Kumar, M. Schulzer, A.J. Stoesslet al. Expectation and the placebo effect in Parkinson's disease patients with subthalamic nucleus deep brain stimulation Mov. Disord., 21 (2006), pp. 1457-2161

Mondaini et al., 2007 N. Mondaini, P. Gontero, G. Giubilei, G. Lombardi, T. Cai, A. Gavazzi et al. Finasteride $5 \mathrm{mg}$ and sexual side effects: how many of these are related to a nocebo phenomenon? J. Sex. Med., 4 (2007), pp. 1708-1712

Morrish et al., 1996 P.K. Morrish, G.V. Sawle, D.J. Brooks An [l8F]dopa-PET and clinical study of the rate of progression in Parkinson's disease Brain, 119 (1996), pp. 585-591

Moseley et al., 2002 J.B. Moseley, K. O'Malley, N.J. Petersen, T.J. Menke, B.A. Brody, D.H. Kuykendallet al. A controlled trial of arthroscopic surgery for osteoarthritis of the knee New Eng. J. Med., 347 (2002), pp. 81-88

Moyad, 2002 M.A. Moyad The placebo effect and randomized trials: analysis of conventional medicine Urol. Clin. North Am., 29 (2002), pp. 125-133

Musial et al., 2007 F. Musial, S. Klosterhalfen, P. Enck Placebo responses in patients with gastrointestinal disorders World J. Gastroenterol., 13 (2007), pp. 3425-3429

Nesse et al., 1980 R.M. Nesse, T. Carli, G.C. Curtis, P.D. Kleinman Pretreatment nausea in cancer chemotherapy: a conditioned response? Psychosom. Med., 42 (1980), pp. 33-36

Neumann et al., 2010 M. Neumann, J. Bensing, M. Wirtz, A. Wubker, C. Scheffer, D. Tauschel, F. Edelhauser, N. Ernstman, H. Pfaff The impact of financial incentives on physician empathy: A study from the perspective of patients with private and statutory health insurance Patient Educ. Couns., 84 (2010), pp. 208-216

Nickel, 1998 J.C. Nickel Placebo therapy of benign prostrate hyperplasia: a 25-month study. Canadian PROSPECT Study Group Br. J. Urol., 81 (1998), pp. 383-387

Nitzan and Lichtenberg, $2004 \mathrm{U}$. Nitzan, P. Lichtenberg Questionnaire survey on use of placebo BMJ, 329 (2004), pp. 944-946

Olanow et al., 2003 C.W. Olanow, C.G. Goetz, J.H. Kordower, A.J. Stoessl, V. Sossi, M.F. Brin et al. A double-blind controlled trial of bilateral fetal nigral transplantation in

Parkinson's disease Ann. Neurol., 54 (2003), pp. 403-414

Olness and Ader, $1992 \mathrm{~K}$. Olness, R. Ader Conditioning as an adjunct in the pharmacotherapy of lupus erythematosus J. Dev. Behav. Pediatr., 13 (1992), pp. 124-125 
Jubb, J., Bensing, J.M. The sweetest pill to swallow: how patient neurobiology can be harnessed to maximise placebo effects. Neuroscience and Biobehavioral Reviews: 2013, 37(10 Part 2), 2709-2720

Petrovic et al., 2002 P. Petrovic, E. Kalso, K.M. Petersson, M. Ingvar Placebo and opioid analgesia imaging a shared neuronal network Science, 295 (2002), pp. 1737-1740

Petrovic et al., 2005 P. Petrovic, T. Dietrich, P. Fransson, J. Andersson, K. Carlsson, M. Ingvar Placebo in emotional processing-induced expectations of anxiety relief activate a generalized modulatory network Neuron, 46 (2005), pp. 957-969

Pollo et al., 2002 A. Pollo, E. Torre, L. Lopiano, M. Rizzone, M. Lanotte, A. Cavanna et al. Expectation modulates the response to subthalamic nucleus stimulation in Parkinsonian patients Neuroreport, 13 (2002), pp. 1383-1386

Pollo et al., 2008 A. Pollo, E. Carlino, F. Benedetti The top-down influence of ergogenic placebos on muscle work and fatigue Eur. J. Neurosci., 28 (2008), pp. 379-388

Pollo et al., 2012 A. Pollo, E. Carlino, L. Vase, F. Benedetti Preventing motor training through nocebo suggestions Eur. J. Appl. Physiol., 112 (11) (2012), pp. 3893-3903

Price et al., 1999 D.D. Price, L.S. Milling, I. Kirsch, A. Duff, G.H. Montgomery, S.S. Nicholls An analysis of factors that contribute to the magnitude of placebo analgesia in an experimental paradigm Pain, 83 (1999), pp. 147-156

Price et al., 2008 D.D. Price, D.G. Finniss, F.A. Benedetti Comprehensive Review of the Placebo Effect: Recent Advances and Current Thought Annu. Rev. Psychol., 59 (2008), pp. 565-590

Raicek et al., 2012 J. Raicek, B.H. Stone, T.J. Kaptchuk Placebos in 19th century medicine: a quantitative analysis of the BMJ BMJ, 345 (2012), p. 38326

Rana et al., 2005 J.S. Rana, A. Mannam, L. Donnell-Fink, E.V. Gervino, F.W. Sellke, R.J. Laham Longevity of the placebo effect in the therapeutic angiogenesis and laser myocardial revascularization trials in patients with coronary heart disease Am. J. Cardiol., 95 (2005), pp. 1456-1459

Raz et al., 2005 A. Raz, J. Fan, M.I. Posner Hypnotic suggestion reduces conflict in the human brain Proc. Natl. Acad. Sci. U. S. A., 102 (2005), pp. 9978-9983

Rief et al., 2009 W. Rief, Y. Nestoriuc, S. Weiss, E. Welzel, A.J. Barsky, S.G. Hofmann Meta-analysis of the placebo response in antidepressant trials J. Affect. Disord., 118 (2009), pp. 1-8

Roberts et al., 1993 A.H. Roberts, D.G. Kewman, L. Mercier, M. Hovell The power of nonspecific effects in healing: implications for psychological and biological treatments Clin. Psychol. Rev., 13 (1993), pp. 375-391

Roscoe et al., 2003 J.A. Roscoe, G.R. Morrow, J.T. Hickok, P. Bushunow, H.I. Pierce, P.J. Flynn et al. The efficacy of acupressure and acustimulation wrist bands for the relief of chemotherapy-induced nausea and vomiting: a URCC CCOP multicenter study J. Pain Symptom Manage., 26 (2003), pp. 731-742

Roscoe et al., 2010 J.A. Roscoe, M. O'Neill, P. Jean-Pierre, C.E. Heckler, T.J. Kaptchuk, P. Bushunowet al. An exploratory study on the effects of an expectancy manipulation on chemotherapy-related nausea J. Pain Symptom Manage., 40 (3) (2010), pp. 379-390

Rosseland et al., 2004 L.A. Rosseland, K.G. Helgesen, H. Breivik, A. Stubhaug Moderate-tosevere pain after knee arthroscopy is relieved by intraarticular saline: a randomized controlled trial Anesth. Analg., 98 (2004), pp. 1546-1551

Roter and Hall, 2006 D.L. Roter, J.A. Hall Doctors Talking With Patients/Patients Talking With Doctors: Improving Communication in Medical Visits Praeger Publishers, Westport, CT, USA (2006)

Roter et al., 2006 D.L. Roter, R.M. Frankel, J.A. Hall, D. Sluyter The expression of emotion through nonverbal behavior in medical visits. Mechanisms and outcomes J. Gen. Intern. Med., 21 (Suppl. 1) (2006), pp. S28-S34 
Jubb, J., Bensing, J.M. The sweetest pill to swallow: how patient neurobiology can be harnessed to maximise placebo effects. Neuroscience and Biobehavioral Reviews: 2013, 37(10 Part 2), 2709-2720

Rouzer and Marnett, 2008 C.A. Rouzer, L.J. Marnett Non-redundant functions of nivel

cyclooxygenases: oxygenation of endocannabinoids J. Biol. Chem., 283 (2008), pp. 80658069

Sandler et al., 2010 A.D. Sandler, C.E. Glesne, J.W. Bodfish Conditioned placebo dose reduction: a new treatment in attention-deficit hyperactivity disorder? J. Dev. Behav. Pediatr., 31 (2010), pp. 369-375

Scott et al., 2008 D.J. Scott, C.S. Stohler, C.M. Egnatuk, H. Wang, R.A. Koeppe, J.K. Zubieta Placebo and nocebo effects are defined by opposite opioid and dopaminergic responses Arch. Gen. Psychiatry, 65 (2008), pp. 220-231

Shapiro and Shapiro, 1997 A.K. Shapiro, E. Shapiro The Powerful Placebo: From Ancient Priest to Modern Physician Johns Hopkins University Press, Baltimore, USA (1997)

Sherman and Hickner, 2007 R.C. Sherman, J. Hickner Physicians use placebos in clinical practice and believe in the mind-body connection J. Gen. Int. Med., 22 (2007), p. 97 Shetty et al., 1999 N. Shetty, J.H. Friedman, K. Kieburtz, F.J. Marshall, D. Oakes The placebo response in Parkinson's disease Clin. Neuropharmacol., 22 (1999), p. 207

Shimizu, 2009 T. Shimizu Lipid mediators in health and disease: enzymes and receptors as therapeutic targets for the regulation of immunity and inflammation Annu. Rev. Pharmacol. Toxicol., 49 (2009), pp. 123-150

Starfield et al., 1981 B. Starfield, C. Wray, K. Hess, R. Gross, P.S. Birk, B.C. D'Lugoff The influence of patient-practitioner agreement on outcome of care Am. J. Publ. Health, 71 (1981), pp. 127-132

Stefano et al., 2001 G.B. Stefano, G.L. Fricchione, B.T. Slingsby, H. Benson The placebo effect and relaxation response: neural processes and their coupling to constitutive nitric oxide Brain Res. Rev., 35 (2001), pp. 1-19

Stewart et al., 1979 M.A. Stewart, I.R. McWhinney, C.W. Buck The doctor-patient relationship and its effect upon outcome J. R. Coll. Gen. Pract., 29 (1979), pp. 77-82 Stewart, 1995 M.A. Stewart Effective physician-patient communication and health outcomes: a review Can. Med. Assoc. J., 152 (1995), pp. 1423-1433 Stewart-Williams and Podd, 2004 S. Stewart-Williams, J. Podd The placebo effect: dissolving the expectancy versus conditioning debate Psychol. Bull., 130 (2) (2004), pp. 324-340

Stockhorst et al., 1998 U. Stockhorst, J.A. Wiener, S. Klosterhalfen, W. Klosterhalfen, C. Aul, H.J. Steingrueber Effects of overshadowing on conditioned nausea in cancer patients: an experimental study Physiol. Behav., 64 (1998), pp. 743-753

U. Stockhorst, E. Gritzmann, K. Klopp, Y. Schottenfeld-Naor, A. Hübinger, H.W. Berresheim et al. Classical conditioning of insulin effects in healthy humans Psychosom. Med., 61 (1999), pp. 424-435

Stockhorst et al., 2000 U. Stockhorst, S. Spennes-Saleh, D. Körholz, U. Göbel, M.E. Schneider, H.J. Steingrüber et al. Anticipatory symptoms and anticipatory immune responses in pediatric cancer patients receiving chemotherapy: features of a classically conditioned response? Brain Behav. Immun., 14 (2000), pp. 198-218

Stockhorst et al., 2006 U. Stockhorst, H.J. Steingrueber, P. Enck, S. Klosterhalfen Pavlovian conditioning of nausea and vomiting Autonom. Neurosci., 129 (2006), pp. 50-57 Stockhorst et al., 2007 U. Stockhorst, P. Enck, S. Klosterhalfen Role of classical conditioning in learning gastrointestinal symptoms World J. Gastroent., 13 (2007), pp. 3430-3437

Strafella et al., 2006 A.P. Strafella, J.H. Ko, O. Monchi Therapeutic application of transcranial magnetic stimulation in Parkinson's disease: The contribution of expectation Neuroimage, 31 (2006), pp. 1666-1672 
Jubb, J., Bensing, J.M. The sweetest pill to swallow: how patient neurobiology can be harnessed to maximise placebo effects. Neuroscience and Biobehavioral Reviews: 2013, 37(10 Part 2), 2709-2720

Sunshine et al., 1964 A. Sunshine, E. Laska, M. Meisner, S. Morgan Analgesic studies of indomethacin as analyzed by computer techniques Clin. Pharmacol. Ther., 5 (1964), pp. 699-707

Tfelt-Hansen et al., 1995 P. Tfelt-Hansen, P. Henry, L.J. Mulder, R.G. Schaeldewaert, J. Schoenen, G. Chazot The effectiveness of the combined oral lysine acetylsalicylate and metoclopramide compared with oral sumatriptan for migraine Lancet, 346 (1995), pp. 923 926

Tilburt et al., 2008 J.C. Tilburt, E.J. Emanuel, T.J. Kaptchuk, F.A. Curlin, F.G. Miller Prescribing "placebo treatments": results of national survey of US internists and rheumatologists BMJ, 337 (2008), p. a1938

Tobler et al., 2005 P.N. Tobler, C.D. Fiorillo, W. Schultz Adaptive coding of reward value by dopamine neurons Science, 307 (2005), pp. 1642-1645

Tyc et al., 1997 V.L. Tyc, R.K. Mulhem, D.R. Barclay, B.F. Smith, A.A. Bieberich Variables associated with anticipatory nausea and vomiting in pediatric cancer patients receiving ondansetron anti-emetic therapy J. Pediatr. Psychol., 22 (1997), pp. 45-58

Van Dulmen and Bensing, 2001 A.M. van Dulmen, J.M. Bensing The effect of context in healthcare a programming study, vol. 3RGO, The Hague (2001) ISBN 9014655-5

van Leeuwen et al., 2006 J.H.S. van Leeuwen, R. Castro, M. Busse, B.L.H. Bemelmans The placebo effect in the pharmacologic treatment of patients with lower urinary tract symptoms Eur. Urol., 50 (2006), pp. 440-452

Vase et al., 2002 L. Vase, J.L. Riley III, D.D. Price A comparison of placebo effects in clinical analgesic trials versus studies of placebo analgesia Pain, 99 (2002), pp. 443-452

Vase et al., 2003 L. Vase, M.E. Robinson, G.N. Verne, D.D. Price The contributions of suggestion, desire, and expectation to placebo effects in irritable bowel syndrome patients. An empirical investigation Pain, 105 (2003), pp. 17-25

Vase et al., 2005 L. Vase, M.E. Robinson, G.N. Verne, D.D. Price Increased placebo analgesia over time in irritable bowel sundrome (IBS) patients is associated with desire and expectation but not endogenous opioid mechanisms Pain, 115 (2005), pp. 338-347

Vase et al., 2009 L. Vase, G.L. Petersen, J.L. Riley III, D.D. Price Factors contributing to large analgesic effects in placebo mechanism studies conducted between 2002 and 2007 Pain, 145 (2009), pp. 36-44

Verheul et al., 2010 W. Verheul, A. Sanders, J. Bensing The effects of physicians' affectoriented communication style and raising expectations on analogue patients' anxiety, affect and expectancies Patient Educ. Couns., 80 (2010), pp. 300-306

Verne et al., 2003 G.N. Verne, M.E. Robinson, L. Vase, D.D. Price Reversal of visceral and cutaneous hyperalgesia by local rectal anesthesia in irritable bowel syndrome (IBS) patients Pain, 105 (2003), pp. 223-230

Volkow et al., 2003 N.D. Volkow, G.J. Wang, Y. Ma, J.S. Fowler, W. Zhu, L. Maynard et al. Expectation enhances the regional brain metabolic and the reinforcing effects of stimulants in cocaine abusers J. Neurosci., 23 (2003), pp. 11461-11468

Waber et al., 2008 R.L. Waber, B. Shiv, Z. Carmon, D. Ariely Commercial features of placebo and therapeutic efficiency J. Am. Med. Assoc., 299 (2008), pp. 1016-1017

Wager et al., 2004 T.D. Wager, J.K. Rilling, E.E. Smith, A. Sokolik, K.L. Casey, R.J. Davidson et al. Placebo-induced changes in fMRI in the anticipation and experience of pain Science, 303 (2004), pp. 1162-1167

Walsh et al., 2000 J.K. Walsh, T. Roth, A. Randazzo, M. Erman, A. Jamieson, M. Scharf et al. Eight weeks of non-nightly use of zolpidem for primary insomnia Sleep, 23 (2000), pp. 1087-1096 
Jubb, J., Bensing, J.M. The sweetest pill to swallow: how patient neurobiology can be harnessed to maximise placebo effects. Neuroscience and Biobehavioral Reviews: 2013, 37(10

Part 2), 2709-2720

Walsh et al., 2002 B.T. Walsh, S.N. Seidman, R. Sysko, M. Gould Placebo response in studies of major depression: variable, substantial, and growing JAMA, 287 (2002), pp. 1840-1847

Walter et al., $2005 \mathrm{H}$. Walter, B. Abler, A. Ciaramidaro, S. Erk Motivating forces of human actions: Neuroimaging reward and social interaction Brain Res. Bull., 67 (2005), pp. 368381

Wells and Kaptchuk, 2012 R. Wells, T.J. Kaptchuk To tell the truth, the whole truth, may do patients harm: The problem of the nocebo effect for informed consent Am. J. Bioethics, 12

(3) (2012), pp. 22-29

White, 1988 K.L. White The Task of Medicine: Dialogue at Wickenburg H.J. Kaiser Family Foundation (1988)

Yang et al., 2007 J. Yang, Y. Yang, J.M. Chen, W.Y. Liu, C.H. Wang, B.C. Lin Effect of oxytocin on acupuncture analgesia in the rat Neuropeptides, 41 (2007), pp. 285-292

Zubieta et al., 2005 J.K. Zubieta, J.A. Bueller, L.R. Jackson, D.J. Scott, Y. Xu, R.A. Koeppe et al. Placebo effects mediated by endogenous opioid activity on $\mu$-opioid receptors J. Neurosci., 25 (2005), pp. 7754-7762

Zubieta et al., 2006 J.K. Zubieta, W.Y. Yau, D.J. Scott, C.S. Stohler Belief or need? Accounting for individual variations in the neurochemistry of the placebo effect Brain Behav. Immun., 20 (2006), pp. 15-26

\section{BOX, TABLES, FiguRES}

\section{Search strategy and selection criteria}

In order to review the literature, an extensive systematic search was carried out of the English languagebased electronic databases of PubMed (including MEDLINE), Web of Science, the Cochrane database and library, PsychLit, BIDS (Bath Information and Data Services), EMBASE and the Science Citation Index. Searching on 'placebo effects' alone yielded 119,774 hits from PubMed, and thus further refinement was necessary. Since there have been such rapid advances in the understanding of placebo mechanisms in recent years, the search was confined to results from 1995 to 2013, unless it later became obvious that there was an earlier seminal work that needed to be included. The keyword search terms used are listed in the Appendix A. As the search started to identify data and information, the title and abstracts were quickly scanned to assess if the publication was indeed suitable.

Fig. 1. The part of the change attributable to the context in placebo effects.
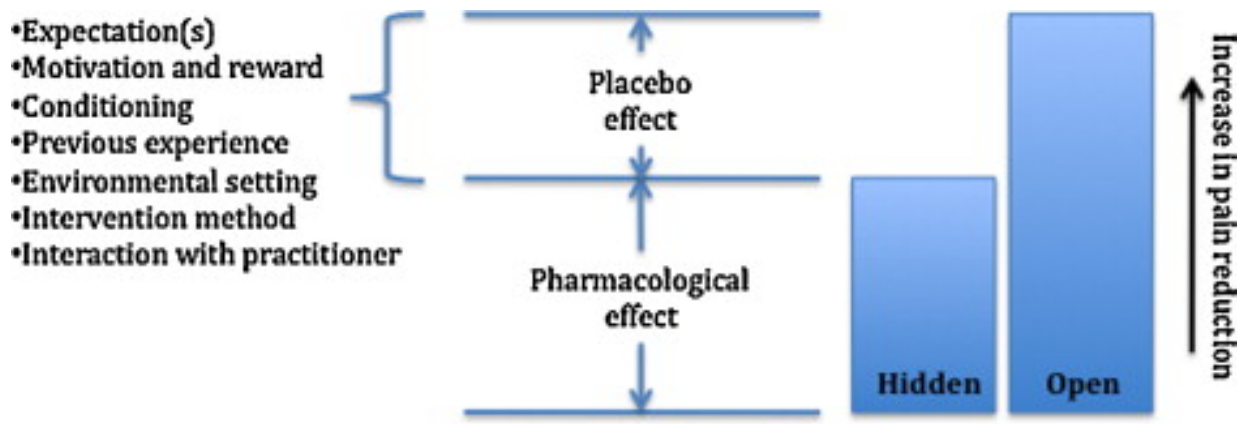
Jubb, J., Bensing, J.M. The sweetest pill to swallow: how patient neurobiology can be harnessed to maximise placebo effects. Neuroscience and Biobehavioral Reviews: 2013, 37(10 Part 2), 2709-2720

Fig. 2. (a) Mid-sagittal view of human brain, indicating brain regions active in placebo effects. Blue shaded areas are involved in opioid mechanisms, green shaded areas in dopamine.Abbreviations: rACC, rostral anterior cingulate cortex; dorsal str., dorsal striatum; NAC, nucleus accumbens; v.str., ventral striatum; thal, thalamus; VLa, ventrolateral thalamus; VA, ventral anterior thalamus; STN, subthalamic nucleus; SNr, substantia nigra pars reticulate; VTA, ventral tegmental area; PAG, periacqueductal grey (Source: Jayne Jubb) pathways.(b) Lateral view of human brain, indicating brain regions active in placebo effects. Blue shaded areas are involved in opioid.Abbreviations: DLPFC, dorsolateral prefrontal cortex; OFC, orbitofrontal cortex; INS, insula (Source: Jayne Jubb) mechanisms.

a

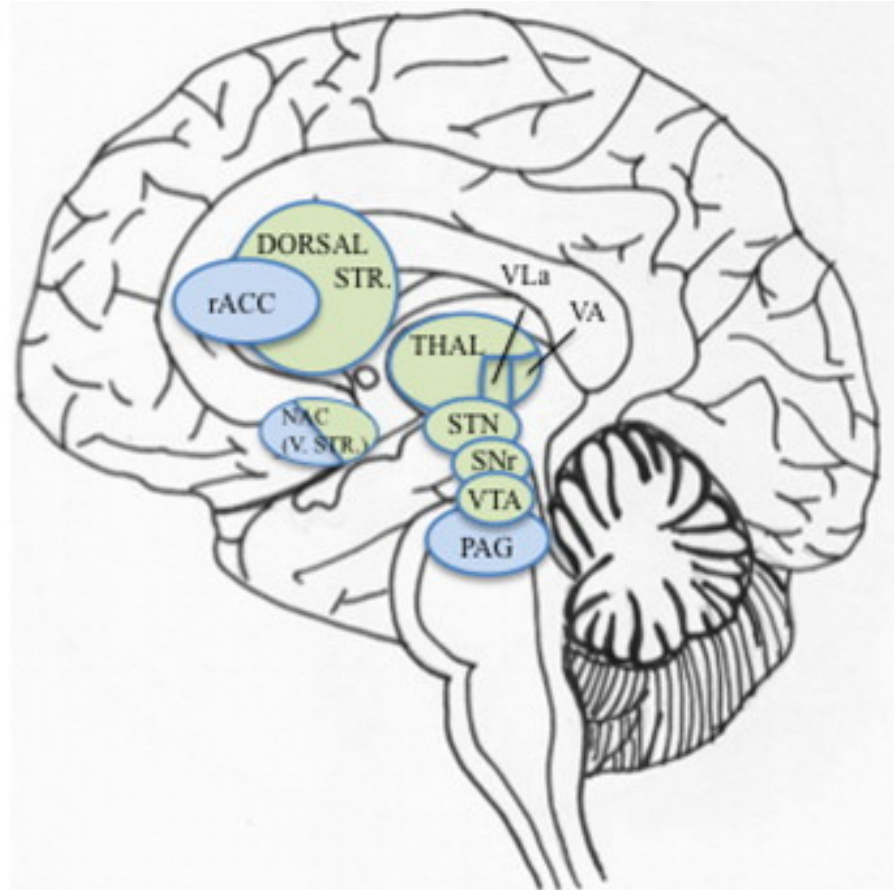

b

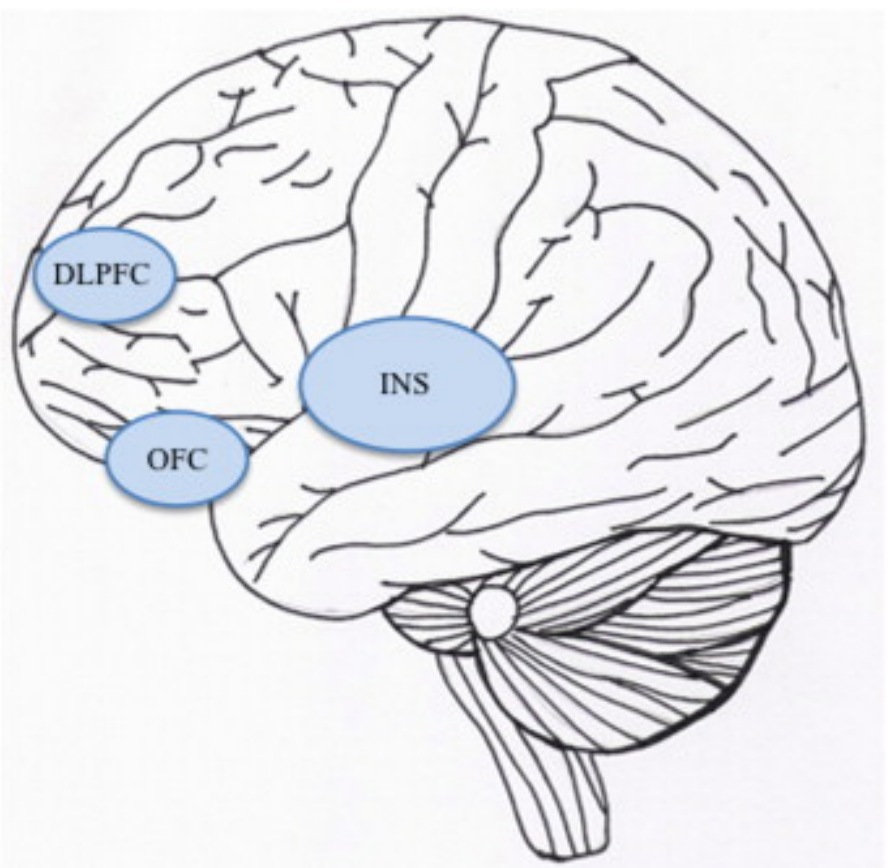


Jubb, J., Bensing, J.M. The sweetest pill to swallow: how patient neurobiology can be harnessed to maximise placebo effects. Neuroscience and Biobehavioral Reviews: 2013, 37(10

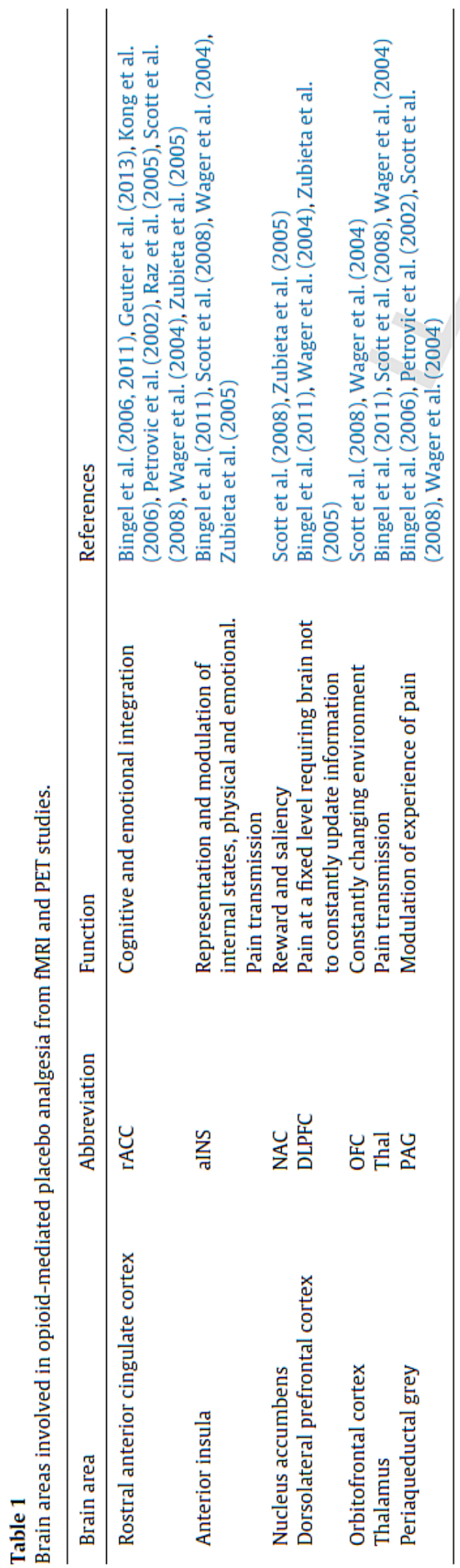


Jubb, J., Bensing, J.M. The sweetest pill to swallow: how patient neurobiology can be harnessed to maximise placebo effects. Neuroscience and Biobehavioral Reviews: 2013, 37(10

Part 2), 2709-2720

Fig. 3. The chain of pain in using verbal negative expectations.

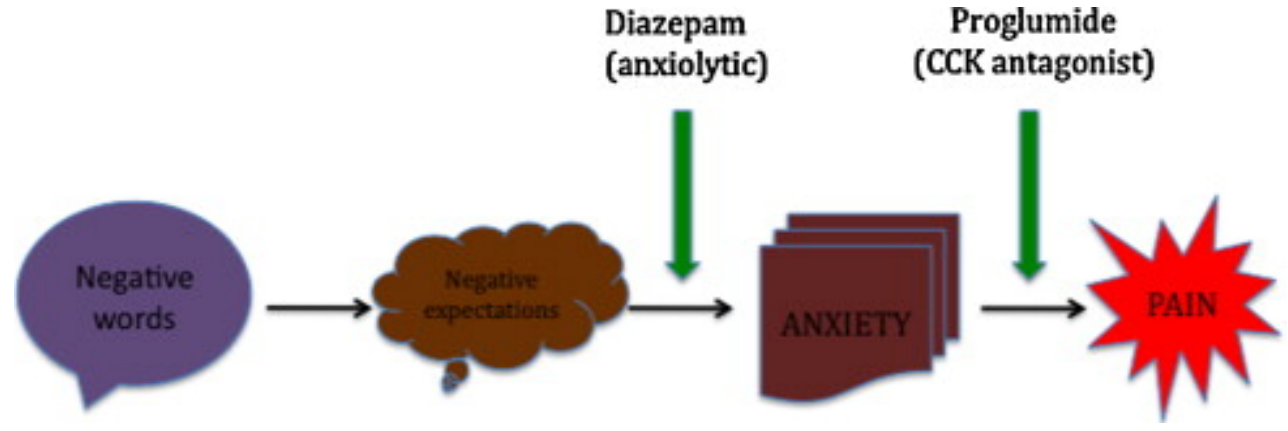

